\title{
Volcanic stratospheric sulfur injections and aerosol optical depth from 500 BCE to 1900 CE
}

\author{
Matthew Toohey ${ }^{1}$ and Michael Sigl ${ }^{2,3}$ \\ ${ }^{1}$ GEOMAR Helmholtz Centre for Ocean Research Kiel, Germany \\ ${ }^{2}$ Laboratory of Environmental Chemistry, Paul Scherrer Institute, 5232 Villigen, Switzerland \\ ${ }^{3}$ Oeschger Centre for Climate Change Research, 3012 Bern, Switzerland \\ Correspondence to: Matthew Toohey (mtoohey@geomar.de)
}

Received: 24 April 2017 - Discussion started: 19 June 2017

Revised: 11 September 2017 - Accepted: 18 September 2017 - Published: 6 November 2017

\begin{abstract}
The injection of sulfur into the stratosphere by explosive volcanic eruptions is the cause of significant climate variability. Based on sulfate records from a suite of ice cores from Greenland and Antarctica, the eVolv2k database includes estimates of the magnitudes and approximate source latitudes of major volcanic stratospheric sulfur injection (VSSI) events from $500 \mathrm{BCE}$ to $1900 \mathrm{CE}$, constituting an update of prior reconstructions and an extension of the record by 1000 years. The database incorporates improvements to the ice core records (in terms of synchronisation and dating) and refinements to the methods used to estimate VSSI from ice core records, and it includes first estimates of the random uncertainties in VSSI values. VSSI estimates for many of the largest eruptions, including Samalas (1257), Tambora (1815), and Laki (1783), are within $10 \%$ of prior estimates. A number of strong events are included in eVolv2k which are largely underestimated or not included in earlier VSSI reconstructions, including events in 540, 574, 682, and $1108 \mathrm{CE}$. The long-term annual mean VSSI from major volcanic eruptions is estimated to be $\sim 0.5 \mathrm{Tg}[\mathrm{S}] \mathrm{yr}^{-1}, \sim 50 \%$ greater than a prior reconstruction due to the identification of more events and an increase in the magnitude of many intermediate events. A long-term latitudinally and monthly resolved stratospheric aerosol optical depth (SAOD) time series is reconstructed from the eVolv2k VSSI estimates, and the resulting global mean SAOD is found to be similar (within 33\%) to a prior reconstruction for most of the largest eruptions. The long-term (500 BCE-1900 CE) average global mean SAOD estimated from the eVolv2k VSSI estimates including a constant "background" injection of stratospheric sulfur is $\sim 0.014,30 \%$ greater than a prior reconstruction. These new long-term reconstructions of past VSSI and SAOD variability give context to recent volcanic forcing, suggesting that the 20th century was a period of somewhat weaker than average volcanic forcing, with current best estimates of 20th century mean VSSI and SAOD values being 25 and $14 \%$ less, respectively, than the mean of the $500 \mathrm{BCE}$ to $1900 \mathrm{CE}$ period. The reconstructed VSSI and SAOD data are available at https://doi.org/10.1594/WDCC/eVolv2k_v2.
\end{abstract}

1

The injection of sulfur into the stratosphere by explosive volcanic eruptions has important ramifications for the Earth's climate. Sulfur-containing gases emitted by volcanic eruptions, including $\mathrm{SO}_{2}$ and $\mathrm{H}_{2} \mathrm{~S}$, lead to the formation of liquid sulfate aerosols. In the stratosphere, sulfate aerosols have a lifetime on the order of years. These aerosols scatter incoming solar radiation and absorb infrared radiation, leading to a net decrease in radiation reaching the Earth's surface and associated cooling (Robock, 2000).

Reconstructions of the history of climatic forcing by past eruptions have a long history (Lamb, 1970) and are an important ingredient in an understanding of past climate variability. Volcanic reconstructions have been extensively used to understand climate variability in instrumental and proxybased climate records (Crowley et al., 2008; Hegerl et al., 2007; Masson-Delmotte et al., 2013; Sigl et al., 2015) and 
have been used to show that volcanism is the dominant natural driver of climate variability in the Earth's recent past (Schurer et al., 2013). Volcanic reconstructions are also increasingly being used to understand the role of sudden climate changes in the evolution of past societies as recorded in documentary and archaeological archives (Ludlow et al., 2013; Oppenheimer, 2011; Toohey et al., 2016a).

Volcanic forcing reconstructions provide essential boundary conditions for climate model simulations which aim to reproduce past climate variability. In one commonly used methodology, climate models take as input reconstructed volcanic forcing datasets, which prescribe certain physical aspects of the volcanic stratospheric sulfate aerosol. More recently, climate models have been coupled with prognostic aerosol microphysical modules, which allow for the explicit simulation of the growth, transport, and removal of stratospheric aerosols (e.g. English et al., 2013; Mills et al., 2016; Timmreck, 2012; Toohey et al., 2011). For these models, simulating the effects of volcanic eruptions on climate requires estimates of the amount of sulfur injected into the stratosphere and the time and location of that injection. Prognostic aerosol modelling, however, comes with an associated computational expense, and many model simulations continue to use prescribed aerosol forcing sets as input. The Easy Volcanic Aerosol (EVA) forcing generator is a simple and flexible module which produces stratospheric aerosol properties for use in climate models when given the sulfur injection magnitude, time, and approximate location (Toohey et al., $2016 b$ ). EVA therefore provides the bridge necessary to allow different types of models to use time series of volcanic stratospheric sulfur injection (VSSI) as a common basis for volcanic forcing.

For eruptions since approximately 1979, VSSIs can be estimated based on satellite observations of the initial $\mathrm{SO}_{2}$ plume (Bluth et al., 1997; Carn et al., 2016; Clerbaux et al., 2008; Guo et al., 2004; Höpfner et al., 2015; Read et al., 1993). Prior to the satellite era, information on the sulfur injection can be inferred from different records, including optical measurements (Sato et al., 1993; Stothers, 1996, 2001), geologic information on the on the eruptive magnitude and volatile content of the erupted magma (Metzner et al., 2012; Scaillet et al., 2003; Self, 2004; Self and King, 1996), and ice cores (Ammann et al., 2003; Clausen and Hammer, 1988; Robock and Free, 1995; Zielinski, 1995). Ice cores in particular provide long records with unequalled temporal accuracy and precision of volcanic eruptions from around the globe (Cole-Dai, 2010; Robock and Free, 1995).

Ice cores were first used to estimate the stratospheric sulfate aerosol mass burden following explosive volcanic eruptions by Clausen and Hammer (1988). Zielinski (1995) used similar techniques to estimate the sulfate aerosol loading resulting from eruptions spanning 2100 years based on chemical analysis of the Greenland GISP2 ice core. Robock and Free (1995) constructed an index of volcanic climate forcing from a compilation of multiple polar ice cores from both hemispheres. Based on a larger compilation of ice cores, Gao et al. (2008) reconstructed both stratospheric sulfur injections and reconstructions of the spatio-temporal spread of aerosol mass in the stratosphere over the time period 5012000. Other volcanic reconstructions (e.g. Ammann et al., 2003; Crowley and Unterman, 2013) have provided estimates of the radiative impacts of past eruptions based on analysis of ice cores without explicitly estimating sulfate aerosol masses or sulfur injections.

Recent improvements to the ice core record of past volcanism (Plummer et al., 2012; Sigl et al., 2014, 2015) motivate a revision and extension of sulfur injection reconstructions. The record of volcanism preserved in Antarctic ice has been improved based on the compilation of a larger set of ice cores, extending back to $500 \mathrm{BCE}$, with a largely static number of cores used to compile an Antarctic average for the past 2000 years (Sigl et al., 2014). An adjustment to previous age models used to date past volcanic events has resulted in better agreement between ice core sulfate signals and cooling signals preserved in tree rings, improving confidence in the accuracy of the new ice core record dating (Sigl et al., 2015).

This paper describes the construction of a new sulfur injection database from ice core records based on newly compiled ice core sulfate composites. It presents the justification for a modification to the method used to convert ice core sulfate fluxes to VSSI compared to past works. Finally, we present estimates of stratospheric aerosol optical depth (SAOD) translated from the VSSI estimates presented here using the EVA forcing generator and compare the resulting record with prior reconstructions. Together, the resulting VSSI and SAOD datasets represent significant updates and improvements to the volcanic forcing datasets (Crowley and Unterman, 2013; Gao et al., 2008) used in numerous prior climate model simulations, including those used in the Paleoclimate Modelling Intercomparison Project (PMIP) Phases 2 and 3 (Schmidt et al., 2011).

\section{Method}

\subsection{Ice core data}

Sulfate (or sulfur) in ice cores can have several sources, of which marine biogenic emissions of dimethyl sulfide and volcanic sulfur emissions are the most important contributions during the pre-industrial era (Cole-Dai, 2010). All reconstructions of volcanic sulfate mass deposition from ice cores agree in the general methodology, in which the nonvolcanic (or background) contribution to the total sulfate (or sulfur) at the ice core site is assumed to be slowly varying and thus can be well approximated by simple functions such as splines, running medians, or a constant value. Upon subtracting the estimated background from the total concentrations, the remaining excess concentrations are attributed to volcanic origin (Gao et al., 2006, 2008; Sigl et al., 2014; Traufetter et al., 2004; Zielinski, 1995). 


\subsubsection{Ice core sulfate composites}

As the basis of the volcanic reconstruction, we used an existing compilation of synchronised volcanic sulfate records from ice cores in Greenland and Antarctica (Sigl et al., 2015) complemented with the GISP2 ice core record from Greenland (Zielinski, 1996) to improve the sampling density, especially during the earlier period of our reconstruction. The compilations use only sulfur and sulfate $\left(\mathrm{SO}_{4}^{2-}\right)$ concentration measurements and exclude measurements of electrical conductivity or acidity since other species than sulfur (e.g. chlorine, fluorine, nitrate, carboxylic acids) may also contribute to the total measured acidity (Clausen et al., 1997; Pasteris et al., 2014). A list of ice cores used is included in Table S1. In summary, the reconstruction is based on ice cores from three sites in Greenland, including NEEM (Sigl et al., 2014, 2015), NGRIP (Plummer et al., 2012), and GISP2 (Zielinski, 1995, 1996) and between 8 and 17 individual ice cores from Antarctica included in the AVS-2k composite over the Common Era (Sigl et al., 2014) extended to earlier dates by the WDC (from 394 BCE) and B40 (from $500 \mathrm{BCE}$ ) ice cores (Sigl et al., 2015).

Volcanic sulfate flux is non-uniform over Greenland and Antarctica, and the shortest ice core records (in time) usually have the largest deposition rates (Gao et al., 2007; Sigl et al., 2014). Taking account of changes in the sample size and pattern over time is a challenging issue in the construction of long-term ice sheet average fluxes. To simplify this process and improve the long-term stability of the resulting records, we preferentially used the longest ice core records currently available, resulting in a relatively constant sample size over most of the Common Era ( $N \geq 12 ; 200-1900$ CE). With the addition of GISP2, only one ice core record has been included into the composite which was not part of the Sigl et al. (2015) database but which has been used in previous compilations (Crowley and Unterman, 2013; Gao et al., 2008). Synchronisation to the NS1-2011 chronology was performed against the NEEM sulfur record, and 85 common stratigraphic age markers (averaging one every 30 years) have been identified (Figs. S1-S3). Over the past 2500 years, the GISP2 sulfate record contains some missing data sections encompassing in total 160 years $(6 \%)$, including the time period 532-606 AD, which includes some of the largest volcanic eruptions in historic times.

Our estimates of the timing of volcanic sulfate enrichment in the ice cores are based on the most recently updated ice core chronologies for Greenland and Antarctica (NS12011 and WD2014, respectively; see Sigl et al., 2015, 2016) and represent the first year in which a sulfate anomaly was detected in the glacio-chemical records. Small adjustments were made in cases in which bipolar eruptions had slightly different ages in Greenland and Antarctica to derive a unified chronology (Sigl et al., 2015). Since the Greenland ice core chronology (NS1-2011) was constrained with more absolute age markers than that from Antarctica (WD2014), a stronger weight was usually given to the Greenland ages. For known historic eruptions - some of which are verified by identifying and characterising tephra in ice cores (Abbott and Davies, 2012; Jensen et al., 2014; Sun et al., 2014) - the exact timing (calendar date, month, season) of the eruptions was used. For the majority of the volcanic events over the past 2500 years, the exact timing of the eruption cannot be constrained with the ice core records alone, since volcanic sulfate has different atmospheric residence times depending on such details as the latitude, season, and injection height of the eruption. Thus the time lag between stratospheric injection at the source and deposition at the ice core site can vary between a few weeks up to a year (Robock, 2000; Toohey et al., 2013).

For each ice core used, deposited $\mathrm{SO}_{4}$ mass (or "flux", in units $\mathrm{kg} \mathrm{km}^{-2}$ ) was previously estimated for all volcanic events exceeding a predefined detection threshold by integrating the sulfate flux exceeding the natural background over the time span of its deposition (Plummer et al., 2012; Sigl et al., 2013, 2014, 2015; Zielinski, 1995, 1996). While major volcanic signals related to eruptions such as Samalas (1257), Tambora (1815), Huyanaputina (1600), or Krakatau (1883) are clearly identified in all ice cores taken from a larger network, the smaller volcanic events may in some cases not be picked up by all ice cores equally. For example, analysis of the GISP2 ice core, which was measured at biannual resolution (Zielinski, 1995), detected fewer volcanic events than in comparably long but higher-resolved ice cores from NEEM and NGRIP. Low annual snowfall rates present in some areas in Antarctica can also occasionally lead to post-depositional changes in the original volcanic sulfate signature, as was shown in the example of the Tambora 1815 event using five ice cores from Dome C (Gautier et al., 2016). Even under such extreme climate conditions present at some areas of East Antarctica, the loss of volcanic signatures from individual ice core records by wind erosion is rather the exception than the rule given that the major volcanic signatures of even much smaller events are continuously captured in virtually all ice cores over Antarctica (Sigl et al., 2014). The large number of ice cores included in the AVS-2k network not only allowed for the firm detection of false positives and more precise quantification of total sulfate flux, but also for a reduction of the detection limit and the identification of additional events that would not exceed the threshold limits set for a single sulfate record. By using an alternative detection approach (AVS-2 $\mathrm{k}_{\mathrm{S}}$ ) based on extracting the event flux directly from a stacked sulfate concentration record characterised by increased signal-to-noise ratios compared to the more noisy individual ice core records, Sigl et al. (2014) extracted an additional 46 volcanic events with sulfate fluxes as low as $1-4 \mathrm{~kg} \mathrm{~km}^{-2}$, whereas the detection limits for the individual ice core sulfate series were close to $3-5 \mathrm{~kg} \mathrm{~km}^{-2}$. With no comparable large network available from Greenland, the detection limit for the three Greenland ice cores in preindustrial times is typically in the range of $3-6 \mathrm{~kg} \mathrm{~km}^{-2}$. After approximately $1900 \mathrm{AD}$, the increased anthropogenic re- 
lease of $\mathrm{SO}_{2}$ into the troposphere from industrial processes masks many of the volcanic signatures during the 20th century in Greenland (Fig. S3). For this reason, we have constrained the present reconstruction to the period before 1900 . For the period thereafter, we recommend the use of estimates utilising larger networks of Greenland ice cores (Crowley and Unterman, 2013; Gao et al., 2008) or from other multiproxy reconstructions (Neely and Schmidt, 2016).

Antarctic and Greenland ice sheet average flux values were then computed based on the available ice core measurements for each volcanic event. In the AVS-2k compilation, individual ice cores were weighted in the overall average in order to account for the spatial variability of deposition over the ice sheet. This was accomplished by first averaging flux values for pre-defined regions or depositional regimes and then averaging the values over the different regions (Sigl et al., 2014). For Greenland, a simple average of the three ice cores was used, since the ice cores show no evidence of systematic differences in their measured values for 48 volcanic events common to all three cores (Fig. S4). In cases when volcanic sulfate was not detected in all three Greenland cores, sulfate flux was set to $50 \%$ of the detection limit for those ice cores without a strong signal. This is motivated by the fact that visual inspection of the data for such cases often revealed the presence of a volcanic signal which did not exceed the detection threshold. These cases only include comparably small volcanic signals: the largest 40 events recorded in the Greenland ice cores since $200 \mathrm{CE}$ all have signals in all three ice cores (providing no gaps in the records). Apparently, the detection threshold had been set differently for the individual ice cores so that many volcanic events detected in NEEM and/or NGRIP have not been extracted for the GISP2 record. NEEM also seems to extract slightly fewer events than NGRIP, potentially owing to the greater background variability of sulfur due to the closer proximity of the ice core site to the ocean emitting biogenic sulfur species. Situated in the centre of Greenland, the NGRIP record has arguably the best ability to capture the atmospheric excess sulfate content from volcanic eruptions, and we thus argue that the simple arithmetic mean is the most realistic metric to describe the true sulfate deposition over Greenland. For Antarctica, occasionally missing values in individual cores have also not been set to "zero" prior to averaging, but the influence on the overall composite value is minimal, as is evident by the comparison with the alternatively stacked composite AVS-2 $\mathrm{k}_{\mathrm{s}}$ (Sigl et al., 2014).

\subsubsection{Ice core uncertainties}

Uncertainty in the timing of volcanic events in ice core records arises from uncertainties in the annual-layer interpretation when establishing the layer counted chronologies. Absolute age uncertainties in the ice core records used in eVolv2k are believed to be on average better than \pm 2 years during the past 1500 years and better than \pm 5 years some
2500 years ago based on comparison to well-dated tree ring records (Adolphi and Muscheler, 2016; Sigl et al., 2015, 2016).

Since the composites for Greenland (in general) and Antarctica (prior to the Common Era) are based on a few ice cores only, we explore in the following how well large-scale sulfate flux over Greenland and Antarctica is reproduced in individual records or pairs of ice core records. For this we use 48 events that are common to all three ice core records in Greenland and 48 events that are recorded in at least 10 ice core records from Antarctica. In both cases, this threshold is more or less equivalent to eruptions with more than $6-7 \mathrm{~kg} \mathrm{~km}^{-2}$ of average sulfate flux (Fig. S4).

For Antarctica, individual ice core records such as B40 $\left(R^{2}=0.88\right)$ and WDC $\left(R^{2}=0.91\right)$ are strongly correlated with the ice-sheet-wide flux values based on a large number $(N \geq 10)$ of individual ice cores (Fig. S4). A composite of only the B40 and WDC records - which is the sample used here prior to the Common Era in Antarctica - produces quite reasonable agreement with the full Antarctic composite for the 48 common events, with a correlation of $R^{2}=0.93$. Similarly, for Greenland, a composite of NEEM and GISP2 shows close correlation $\left(R^{2}=0.98\right)$ with the three-ice-core Greenland composite, and correlations of single ice core values vs. the full composite are only slightly smaller, with GISP2 $\left(R^{2}=0.76\right)$ showing the weakest agreement with the overall composite and NGRIP $\left(R^{2}=0.89\right)$ having the highest correlation. The high level of correlation - especially over Antarctica where a large number of individual records contributes to the composite - indicates that the lack of replication of the Tambora signal observed at Dome C (Gautier et al., 2016) is most likely a phenomenon specific to the wind-exposed Antarctic plateau and that, in general, individual ice core records are able to capture a large portion of the large-scale sulfate flux. In other words, the strong correlations between ice sheet composites and the single-site records support the idea that valuable information on largescale sulfate flux and therefore stratospheric aerosol burdens can be extracted even from a small number of ice cores from well-placed sites.

Uncertainties in the Antarctic composite sulfate fluxes in AVS-2k are taken as reported by Sigl et al. (2015). From 1$2000 \mathrm{CE}$, the uncertainty in the Antarctic mean is quantified by the standard error of the mean (SEM) of the individual ice core flux values. Typical (root mean square) uncertainties for this period in the Antarctic composites are approximately $13 \%$. Before $1 \mathrm{CE}$, when only two ice cores are used in the construction of the Antarctic composite, a constant uncertainty value of $26 \%$ is assumed based on regression analysis between AVS-2k (the ice sheet average) and the composite of WDC and B40 over the 1-2000 CE period (see Sigl et al., 2015).

Special consideration is paid to uncertainties in the Greenland composite sulfate flux due to the small sample size. Assuming that the fluxes retrieved from each ice core represent 
the true ice sheet average plus some normally distributed independent random error, estimates of the error variance for each ice core can be estimated (Appendix A). This analysis produces estimates of 46,45 , and $33 \%$ for NEEM, NGRIP, and GISP2, respectively (Fig. S5). Using standard error propagation rules, we estimate that when all three ice cores are used in an ice sheet composite, the resulting uncertainty is approximately $22 \%$ and two-core composites take uncertainties of approximately $32 \%$ (NEEM plus NGRIP), $28 \%$ (NEEM plus GISP2), and $28 \%$ (NGRIP plus GISP2).

\subsection{Injection locations and dates}

The locations and dates of stratospheric sulfur injections can be assigned based on matching ice core sulfate signals with observed historic eruptions. Here, following prior work (e.g. Crowley and Unterman, 2013; Plummer et al., 2012; Sigl et al., 2013), we use the Volcanoes of the World online eruption database (Global Volcanism Program, 2013) and other sources of information to assign locations and dates to a number of events in the combined Greenland and Antarctic sulfate event inventory (Table 1). Such matches carry some degree of uncertainty and subjectivity. In some cases, the matches can be made with a high degree of confidence based on the temporal coincidence of exceptional sulfate signals with similarly exceptional eruptions, e.g. Tambora (1815) and Laki (1783). Chemical analysis of tephra extracted from ice cores has been used to strengthen the matches for cases like Samalas (1257, Lavigne et al., 2013) and Changbaishan (946, Sun et al., 2014). In other cases, matches are based on little more than temporal coincidence between an ice core sulfate signal and an identified major eruption - such matches are prone to reexamination when ice core timescales are adjusted or the eruption catalogue is updated. For this exercise, we have attempted to err on the side of caution and have discarded some matches used in prior work. For example, the large mid-15th century ice core sulfate signal originally attributed to $1452 / 53$ (Gao et al., 2006) and recently refined by independent annual-layer counting to 1458 (Plummer et al., 2012; Sigl et al., 2013) often attributed to the Kuwae caldera, Vanuatu $\left(17^{\circ} \mathrm{S}\right)$ is considered unidentified here.

For the remaining majority of ice core sulfate signals which are not easily matched to a known eruption, approximate eruption latitudes are assigned based on the presence or lack of simultaneous signals in both Greenland and Antarctic ice core composites. Signals occurring synchronously (given small possible dating uncertainties) in both Greenland and Antarctic composites are attributed to tropical eruptions, while those with signals in only one hemisphere are assumed to be extratropical in origin following Sigl et al. (2015). Representative latitudes for unidentified eruptions can be based on the latitudinal distribution of identified eruptions. Based on the Holocene eruption database (Global Volcanism Program, 2013), we find average latitudes of extrat- ropical $(|\varphi|>25), \mathrm{VEI} \geq 5$ eruptions of $48^{\circ} \mathrm{N}$ and $42^{\circ} \mathrm{S}$, and an average tropical eruption latitude of $2^{\circ} \mathrm{N}$. For simplicity and symmetry, we adopt a convention of assigning unknown tropical eruptions a latitude of $0^{\circ} \mathrm{N}$ and extratropical eruptions a latitude of $45^{\circ} \mathrm{N}$ or S. Consistent with Crowley and Unterman (2013), unknown eruptions are assigned an eruption date of 1 January.

\subsection{Stratospheric sulfate injection estimation}

The mass of sulfur injected into the stratosphere by an eruption $\left(M_{\mathrm{S}}\right)$ is eventually deposited onto the Earth's surface. Assuming all injected sulfur is converted to sulfate aerosols before deposition, the mass of total sulfate flux to the surface $\left(D_{\mathrm{SO}_{4}}\right)$ is simply $3 M_{\mathrm{S}}$ due to the ratio of the molecular mass of $\mathrm{SO}_{4}$ to the atomic mass of sulfur. From ice cores, the sulfate "flux" $\left(f_{\mathrm{SO}_{4}}\right)$ is derived, which represents the local accumulated sulfate mass density in units of $\mathrm{kg} \mathrm{km}^{-2}$. If this flux was uniform over the Earth, estimating $D_{\mathrm{SO}_{4}}$ (and thereby $M_{\mathrm{S}}$ ) would simply require multiplying the flux by the surface area of the Earth. Since the deposition is not spatially uniform, a transfer function is required to convert flux values from any location or area to estimates of $D_{\mathrm{SO}_{4}}$ to account for the spatial inhomogeneity of deposition (Gao et al., 2007; Toohey et al., 2013). Assuming that the deposition pattern is consistent for all events for any location or region on Earth, a transfer function, $L^{\text {global }}$, can be defined as

$L^{\text {global }}=\frac{D_{\mathrm{SO}_{4}}}{f_{\mathrm{SO}_{4}}}=\frac{3 M_{\mathrm{S}}}{f_{\mathrm{SO}_{4}}}$.

Clausen and Hammer (1988) derived the first global transfer functions based on analysis of the radioactive products of nuclear weapons testing (NWT) in the 1950s and 1960s, with $L^{\text {global }}$ defined by the ratio of the estimated release of radioactive material and estimates of the radioactive flux from analysis of ice cores. Clausen and Hammer (1988) then used the global transfer functions to estimate the sulfate aerosol loading from a number of past eruptions by applying the transfer function for each ice core individually to the volcanic fluxes for each core and averaging the result for a best estimate.

Gao et al. (2007) suggested that the sulfate fluxes to Greenland and Antarctica can be used separately as proxies for the Northern Hemisphere (NH) and Southern Hemisphere (SH) sulfate loading. In this methodology, transfer functions are required to connect the ice sheet sulfate fluxes from Greenland and Antarctica ( $f^{\mathrm{G}}, f^{\mathrm{A}}$, respectively, with the subscript " $\mathrm{SO}_{4}$ " discarded hereafter for brevity) to the total hemispheric deposited sulfate ( $D^{\mathrm{NH}}$ and $\left.D^{\mathrm{SH}}\right)$. By defining a variable, $\alpha$, which represents the ratio of NH to global deposited sulfate and therefore the proportion of the total sulfur injection, $M_{\mathrm{S}}$, which is transported to and deposited over the $\mathrm{NH}$,

$\alpha=\frac{D^{\mathrm{NH}}}{D^{\text {global }}}=1-\frac{D^{\mathrm{SH}}}{D^{\text {global }}}$, 
Table 1. Proposed matches of ice core sulfate signals to volcanic eruptions. Matches are based on those listed by Sigl et al. (2013), with appropriate time shift applied due to updated ice core timescales (Sigl et al., 2015), except where noted. Volcano names, eruption dates, and eruption numbers are taken from the Volcanoes of the World database provided online by the Global Volcanism Program (2013), except where noted.

\begin{tabular}{|c|c|c|c|c|c|c|c|}
\hline $\begin{array}{l}\text { Ice } \\
\text { year }\end{array}$ & $\begin{array}{l}\text { Eruption } \\
\text { year }\end{array}$ & $\begin{array}{l}\text { Eruption } \\
\text { month }\end{array}$ & $\begin{array}{l}\text { Eruption } \\
\text { day }\end{array}$ & $\begin{array}{l}\text { Volcano } \\
\text { latitude }\end{array}$ & $\begin{array}{l}\text { Volcano } \\
\text { name }\end{array}$ & VEI & $\begin{array}{l}\text { GVP } \\
\text { eruption } \\
\text { number }\end{array}$ \\
\hline 1887 & 1886 & 6 & 10 & -38.12 & Okataina (Tarawera) & 5 & 14506 \\
\hline 1884 & 1883 & 8 & 27 & -6.10 & Krakatau & 6 & 15589 \\
\hline 1875 & 1875 & 4 & 1 & 65.03 & Askja $^{1}$ (Öskjuvatn Caldera) & 5 & 12911 \\
\hline 1873 & 1873 & 1 & 8 & 64.40 & Grímsvötn & 4 & 12818 \\
\hline 1862 & 1861 & 12 & 28 & 0.32 & Makian & 4 & 16685 \\
\hline 1856 & 1856 & 9 & 25 & 42.06 & Hokkaido-Komagatake $^{1}$ & 4 & 18567 \\
\hline 1853 & 1853 & 4 & 22 & 42.50 & Toya $(\mathrm{O}-\mathrm{Usu})$ & 4 & 18598 \\
\hline 1836 & 1835 & 1 & 20 & 12.98 & Cosigüina & 5 & 15718 \\
\hline 1832 & 1831 & - & - & 19.52 & Babuyan Claro & 4 & 16880 \\
\hline 1823 & 1822 & 10 & 8 & -7.25 & Galunggung & 5 & 15718 \\
\hline 1815 & 1815 & 4 & 10 & -8.25 & Tambora $^{2}$ & 7 & 16231 \\
\hline 1783 & 1783 & 6 & 15 & 64.40 & Grímsvötn (Laki) ${ }^{3}$ & 4 & 12809 \\
\hline 1766 & 1766 & 4 & 5 & 63.98 & Hekla (Bjallagigar) & 4 & 12745 \\
\hline 1756 & 1755 & 10 & 17 & 63.63 & Katla & 5 & 12674 \\
\hline 1739 & 1739 & 8 & 19 & 42.69 & Shikotsu (Tarumai) & 5 & 18612 \\
\hline 1721 & 1721 & 5 & 11 & 63.63 & Katla $^{1}$ & 5 & 12673 \\
\hline 1708 & 1707 & 12 & 16 & 35.36 & Fujisan & 5 & 17452 \\
\hline 1673 & 1673 & 5 & 20 & 1.38 & Gamkonora & 5 & 16584 \\
\hline 1667 & 1667 & 9 & 23 & 42.69 & Shikotsu (Tarumai) & 5 & 18610 \\
\hline 1641 & 1640 & 12 & 26 & 6.11 & Parker & 5 & 16694 \\
\hline 1601 & 1600 & 2 & 17 & -16.61 & Huaynaputina & 6 & 11795 \\
\hline 1595 & 1595 & 3 & 9 & 4.89 & Nevado del Ruiz & 4 & 11279 \\
\hline 1585 & 1585 & 1 & 10 & 19.51 & Colima & 4 & 10414 \\
\hline 1512 & 1510 & 7 & 25 & 63.98 & Hekla & 4 & 12739 \\
\hline 1477 & 1477 & 2 & 1 & 64.63 & Bárðarbunga (Veidivötn) & 6 & 12865 \\
\hline 1258 & 1257 & $7( \pm 3)$ & - & -8.42 & Rinjani (Samalas) $)^{4}$ & 7 & 20843 \\
\hline 946 & 946 & $11( \pm 2)$ & - & 41.98 & Changbaishan ${ }^{5}$ & 7 & 19644 \\
\hline 939 & 939 & $4( \pm 2)$ & - & 63.63 & Katla (Eldgjá) ${ }^{6}$ & 4 & 19938 \\
\hline 879 & - & - & - & 64.63 & Bárðarbunga (Vatnaöldur) & 4 & 12854 \\
\hline 853 & - & - & - & 61.38 & Churchill $^{7}$ & 6 & 20422 \\
\hline 236 & - & 3 & $15( \pm 20)$ & -38.82 & Taupo $^{8}$ & 6 & 14553 \\
\hline
\end{tabular}

\footnotetext{
${ }^{1}$ Newly proposed match.

2 Date of most explosive phase of eruption, from Sigurdsson and Carey (1989).

3 Date of most explosive phase of eruption, from Thordarson and Self (2003).

4 Attribution and date estimate from Lavigne et al. (2013).

5 Attribution from Sun et al. (2014). Date based on inference from historical documents (Hayakawa and Koyama, 1998; Xu et al., 2013).

6 Date (including estimate of season) from Oppenheimer et al. (2017).

7 Attribution from Jensen et al. (2014).

${ }^{8}$ Eruption season derived from dendrochronological evidence (Hogg et al., 2012).
}

we can write transfer functions for the ice sheets of each hemisphere:

$L^{\mathrm{G}}=\frac{D^{\mathrm{NH}}}{f^{\mathrm{G}}}=\frac{3 \alpha M_{\mathrm{S}}}{f^{\mathrm{G}}}$,

$L^{\mathrm{A}}=\frac{D^{\mathrm{SH}}}{f^{\mathrm{A}}}=\frac{3(1-\alpha) M_{\mathrm{S}}}{f^{\mathrm{A}}}$.
From Eqs. (3) and (4), we can write an expression for $M_{\mathrm{S}}$ as a function of the measured Greenland and Antarctic fluxes and the transfer functions:

$M_{\mathrm{S}}=\frac{L^{\mathrm{G}} f^{\mathrm{G}}}{3}+\frac{L^{\mathrm{A}} f^{\mathrm{A}}}{3}$.

While the hemispheric partitioning coefficient $\alpha$ is not required to calculate $M_{\mathrm{S}}$ via Eq. (5), it can be used as a proxy for the hemispheric asymmetry of the volcanic radiative forcing. In practice, the eVolv2k database includes the ratio $(R)$ 
of the estimated NH to SH deposited sulfate:

$R=\frac{L^{\mathrm{G}} f^{\mathrm{G}}}{L^{\mathrm{L}} f^{\mathrm{L}}}$,

where $R$ is simply related to $\alpha$ as $R=\alpha /(\alpha-1)$.

Gao et al. (2007) derived values of the hemispheric transfer functions $L^{\mathrm{G}}$ and $L^{\mathrm{A}}$ separately for tropical and extratropical eruptions. For tropical eruptions, Gao et al. (2007) used measurements of nuclear radioactivity from ice cores (Clausen and Hammer, 1988) and revised estimates of the stratospheric injection of radioactive fallout from NWT. Since the partitioning of radioactive material between the $\mathrm{NH}$ and $\mathrm{SH}$ after the NWT in the tropics is uncertain, Gao et al. (2007) assumed that between $1 / 2$ to $2 / 3$ of the radioactive material was transported into the Northern Hemisphere (i.e. $0.5<\alpha<0.66$ ), which lead to estimates for $L^{\mathrm{G}}$ ranging from 0.75 to $1.0 \times 10^{9} \mathrm{~km}^{2}$. For $L^{\mathrm{A}}$, Gao et al. (2007) used estimates of the sulfur injection by the 1991 eruption of Pinatubo and measured sulfate in Antarctic ice cores. We revisit that calculation here based on updated data. According to analysis of satellite retrievals (Guo et al., 2004), Pinatubo injected $18 \pm 4 \mathrm{Tg}$ of $\mathrm{SO}_{2}$ into the lower tropical stratosphere, amounting to $9 \pm 2 \mathrm{Tg}$ [S]. Satellite records also show a fairly even transport of aerosol between the $\mathrm{NH}$ and $\mathrm{SH}$, suggesting $\alpha \approx 0.5$. The Antarctic average sulfate flux following Pinatubo is approximately $11 \mathrm{~kg} \mathrm{~km}^{-2}$ (Crowley and Unterman, 2013; Sigl et al., 2014). Using these values in Eq. (4) leads to an estimate of $L^{\mathrm{A}}$ of $1.2 \pm 0.3 \times 10^{9} \mathrm{~km}^{2}$ or approximately $0.9-1.5 \times 10^{9} \mathrm{~km}^{2}$. This calculation is only slightly changed when considering the potential impact of the August 1991 Cerro Hudson eruption in Chile, which injected an estimated $0.75 \mathrm{Tg}[\mathrm{S}]$ into the stratosphere (Bluth et al., 1997). In this case, again noting that the observed SAOD after Pinatubo was balanced between the NH and SH, we infer that the SH loading was about half of the total sulfur injection by Pinatubo and Cerro Hudson, around $4.9 \pm 1 \mathrm{Tg}[\mathrm{S}]$, which leads to a value for $L^{\mathrm{A}}$ of $1.3 \pm 0.3 \times 10^{9} \mathrm{~km}^{2}$.

The hemispheric transfer function estimates from the NWT results (for Greenland) and the Pinatubo case study (for Antarctica) are both consistent with a value of $1.0 \times$ $10^{9} \mathrm{~km}^{2}$. There is no reason that the transfer functions should need to be the same for both Greenland and Antarctica - in fact, given the spatial variability of simulated sulfate deposition patterns over the globe (Gao et al., 2007; Toohey et al., 2013), it would perhaps be surprising that the values are the same. On the other hand, ice-core-derived flux estimates for identified tropical eruptions cluster around equal values for Antarctica and Greenland (Toohey et al., 2016a); therefore applying equal weight to the two hemispheric ice sheets in the estimation of the global total seems to be a justifiable simplification.

A transfer function value for tropical eruptions of $1.0 \times$ $10^{9} \mathrm{~km}^{2}$ is numerically identical to that derived by Gao et al. (2007); however, there is a subtle difference in our implementation. Our interpretation is that this transfer function relates the sulfate flux values with atmospheric sulfate mass (either the hemispheric deposited sulfate $\mathrm{DSO}_{4}$ or, equivalently, the theoretical maximum sulfate mass loading $3 M_{\mathrm{S}}$ ). In contrast, Gao et al. (2007) used the same value to estimate the volcanic sulfate aerosol mass loading, which is different since sulfate aerosols include not only the mass of sulfate, but also that of water, as sulfate aerosols in the stratosphere are usually assumed to be $25 \%$ water by mass. To calculate the mass of sulfate aerosols from the mass of sulfate requires scaling by a factor of $4 / 3$; therefore, our revised transfer function estimate is effectively $33 \%$ larger than that of Gao et al. (2007).

For extratropical eruptions, Gao et al. (2007) introduced a transfer function of $L^{\mathrm{G}}=L^{\mathrm{A}}=0.57 \times 10^{9} \mathrm{~km}^{2}$ based on analysis of ice core radioactivity resulting from NWT at high latitudes and on output from volcanic sulfate transport simulations with a general circulation model. The use of a smaller transfer function for extratropical eruptions seems appropriate since a larger proportion of the sulfate from such eruptions is likely to be deposited in the extratropics compared to tropical eruptions, necessitating a smaller transfer function to estimate the global deposited sulfate (or injected mass). We retain the value of $0.57 \times 10^{9} \mathrm{~km}^{2}$ here, but again interpret it rather as a transfer function between ice-core-derived sulfate flux and sulfate loading (not sulfate aerosol loading), producing an effective $33 \%$ increase in the transfer function compared to that of Gao et al. (2007). The threshold latitude separating tropical and extratropical eruptions is set to $\pm 25^{\circ}$ based on satellite-based estimates of the "edges" of the stratospheric tropical pipe (Neu et al., 2003).

While it is thought that the majority of sulfate aerosol arising from extratropical eruptions is contained within the hemisphere of the eruption (Oman et al., 2006), it does seem possible that in some cases sulfate from extratropical eruptions may cross the Equator in large enough quantities to be recorded in the ice sheets of the opposite hemisphere. Modelling results suggest that extratropical eruptions can lead to ice sheet flux in the opposite hemisphere of the eruption around $10 \%$ that of the hemisphere of eruption, which is likely to produce detectable signals only for the largest such eruptions (Toohey et al., 2016a). In such cases, we used the extratropical transfer function to estimate the sulfate injection of the hemisphere of the eruption and the tropical transfer function to estimate the injection to the other hemisphere. In the current eVolv2k version, the only significant eruption for which this rule applies is the $236 \mathrm{CE}$ Taupo event, for which sulfate signals in both Antarctica and Greenland are attributed to the $\mathrm{SH}$ eruption.

It should also be noted that the method introduced above assumes that the ice core sulfate flux is directly proportional to the stratospheric injection. In reality, some of the sulfate deposited on ice sheets may come from volcanic sulfur emissions into the troposphere. Of particular importance are effusive (i.e. non-explosive) eruptions from Iceland, which under the right meteorological conditions may produce large sul- 
fate deposition over Greenland even when the stratospheric injection is minimal. Crowley and Unterman (2013) adjusted the Greenland flux values for the 1783 Laki eruption, deriving a ratio of stratospheric to total sulfate flux of 0.15 based on analysis of the "far-field" Mt. Logan ice core. The proportion of Laki's stratospheric sulfur injection is indeed highly uncertain (Lanciki et al., 2012; Schmidt et al., 2012), and to date little quantitative information on the stratospheric-totropospheric partitioning of sulfur injection is available for other Icelandic eruptions of the past 2500 years. Geological records suggest that purely effusive eruptions in Iceland are rare and that the eruption of Laki was characterised by both explosive and effusive phases (Thordarson and Larsen, 2007). Until an objective criterion can be established to quantify the proportion of ice core sulfate representing the stratospheric sulfate burden, we have chosen to maintain the assumption that all sulfate is stratospheric but stress that this is a rather important potential source of uncertainty.

\subsubsection{Uncertainty in VSSI}

The VSSI estimates carry significant uncertainty due to errors in the ice core flux measurements and, more importantly, uncertainties in the transfer functions used to convert the ice core flux composites to estimates of VSSI.

Systematic uncertainties describe potential errors that are static, leading to overall bias in the estimated quantity. The most likely source of systematic error in the VSSI estimates comes from the uncertainty in the transfer functions $L^{\mathrm{G}}$ and $L^{\mathrm{A}}$. For $L^{\mathrm{G}}$, the uncertain distribution of NWT radioactive material between the $\mathrm{NH}$ and $\mathrm{SH}$ leads to an uncertainty of $\sim 15 \%$, although this uncertainty could be larger if one allows for the possibility of a larger range of possible hemispheric partitioning ratios. Uncertainty in $L^{\mathrm{G}}$ is also strongly connected to uncertainties in the amount of radioactive material released by NWT and its partitioning between the stratosphere and troposphere. For $L^{\mathrm{A}}$, uncertainty arises due to the uncertainty in the VSSI produced by the 1991 Pinatubo eruption. Systematic uncertainties in the transfer functions for extratropical eruptions, currently based mostly on the climate model simulations of Gao et al. (2007), are difficult to quantify but likely larger than those of tropical eruptions.

Random errors in the VSSI estimates may be present because of finite sampling in the estimation of the ice sheet average flux from a finite sample of ice cores and because the ice sheets sample only a portion of the overall hemispheric deposited sulfate, which might vary from case to case because of variability in atmospheric transport and deposition processes. Using standard error propagation rules, the random error in the total sulfur injection $\sigma_{M_{\mathrm{S}}}$ due to random errors in the ice sheet composites and the transfer functions is given by

$$
\sigma_{M_{\mathrm{S}}}=\sqrt{\left\{\begin{array}{l}
\left(\frac{L^{\mathrm{G}} f^{\mathrm{G}}}{3}\right)^{2}\left[\left(\frac{\sigma_{L^{\mathrm{G}}}}{L^{\mathrm{G}}}\right)^{2}+\left(\frac{\sigma_{f^{\mathrm{G}}}}{f^{\mathrm{G}}}\right)^{2}\right] \\
+\left(\frac{L^{\mathrm{A}} f^{\mathrm{A}}}{3}\right)^{2}\left[\left(\frac{\sigma_{L^{\mathrm{A}}}}{L^{\mathrm{A}}}\right)^{2}+\left(\frac{\sigma_{f^{\mathrm{A}}}}{f^{\mathrm{A}}}\right)^{2}\right]
\end{array}\right.}
$$

The relative uncertainties in the composite ice sheet fluxes $\left(\sigma_{f^{\mathrm{G}}}, \sigma_{f^{\mathrm{A}}}\right)$ are as described in Sect. 2.1.2. The random error of the transfer functions $\left(\sigma_{L^{\mathrm{G}}}, \sigma_{L^{\mathrm{A}}}\right)$ is presently impossible to estimate from observations. Model simulations of volcanic sulfur injection and its evolution suggest that the proportion of sulfur injected into the stratosphere and later deposited on ice sheets can vary substantially due to variations in the meteorological state (Toohey et al., 2013). We take modelbased estimates of this variability quantified at the $1 \sigma$ level as 16 and $9 \%$ for Greenland and Antarctica, respectively, as the present best estimates of this representativeness error (Toohey et al., 2013).

\subsection{Aerosol optical depth estimation}

The Easy Volcanic Aerosol (EVA) version 1 forcing generator (Toohey et al., 2016b) is used here to translate sulfur injections into spatio-temporally resolved estimates of the optical properties of volcanic aerosols. We focus here on the variation in stratospheric aerosol optical depth (SAOD) at the mid-visible wavelength of $550 \mathrm{~nm}$.

The EVA module takes stratospheric sulfur injection estimates as input and outputs vertically and latitudinally varying aerosol optical properties designed for easy implementation in climate models. The spatio-temporal structure of the EVA output fields is based on a simple three-box model of stratospheric transport, with timescales of mixing and transport based on fits to satellite observations of the 1991 Pinatubo eruption. Vertical and horizontal shape functions are assigned to each of the three boxes, again based on the observed extinction of Pinatubo aerosols. Internally, EVA first calculates the transport of sulfate mass between the three regions and then applies a scaling procedure to translate sulfate mass into mid-visible SAOD. This scaling is linear for most eruptions and is based on retrievals of SAOD and total sulfur injection from the 1991 Pinatubo eruption. Following Crowley and Unterman (2013), a non-linear scaling is applied for very large eruptions: in EVA, the nonlinear scaling applies only to eruptions greater in magnitude than Tambora. EVA allows also for the consideration of a constant, non-zero stratospheric sulfur injection representing the cross-tropopause transport of naturally produced gases, including carbonyl sulfide (Crutzen, 1976; Kremser et al., 2016), which gives rise to the "background" stratospheric sulfate aerosol layer (Junge et al., 1961). The smallest satellite-observed SAOD, which occurred around the year 2000 , is used to estimate a constant background sulfur injec- 
tion of $0.2 \mathrm{Tg} \mathrm{yr}^{-1}$, which agrees well with other estimates (Sheng et al., 2015).

The SAOD results shown hereafter, produced by the EVA forcing generator using the eVolv2k VSSI database, are denoted as "EVA(eVolv2k)". This naming convention is used to emphasise the two-step nature of the SAOD reconstruction and encourage clarity in future cases when e.g. EVA is used with other input datasets. SAOD results are shown in terms of either monthly, annual, or centennial means - it should be noted that peak SAOD values can vary substantially depending on the temporal resolution of the record.

\subsection{Comparison datasets}

\subsubsection{Ice sheet composite sulfate flux}

The ICI reconstruction (Crowley and Unterman, 2013) provides ice-core-based composite fluxes for the $\mathrm{NH}$ and $\mathrm{SH}$ over the period 800-2000 CE. SH fluxes are based on ice core records from Antarctica, while NH fluxes come from Greenland cores plus one core from Mt. Logan, Alaska. We rescaled the sulfate flux reported for Laki (1783) to undo the correction applied by the authors to account for tropospheric vs. stratospheric injection by dividing by a factor of 0.15 . The IVI2 database (Gao et al., 2008) does not directly provide ice core composite fluxes. However, by inverting the scaling procedure described by Gao et al. (2007), we have reproduced hemispheric composite fluxes based on the reported estimates of stratospheric sulfate aerosol injection over the period 500-2000. We validated these results by comparing with the few sample fluxes reported by Gao et al. (2007).

\subsubsection{Volcanic stratospheric sulfur injection}

Global VSSI estimates over the period 501-2000 are extracted from the IVI2 database (Gao et al., 2008) by first summing the reported hemispheric stratospheric sulfate aerosol injections. The sulfate aerosol masses of IVI2 are computed assuming $25 \%$ water content, so multiplication by a factor of 0.75 is required to convert sulfate aerosol mass into sulfate mass. Finally, conversion from sulfate mass to sulfur mass is computed based on the ratio of molecular weights.

The VolcanEESM database (Mills et al., 2016; Neely and Schmidt, 2016) contains estimates of total $\mathrm{SO}_{2}$ emissions by volcanic eruptions from 1850 to 2015 . For the pre-satellite era (1850 to 1979), the dataset combines the most recent volcanic sulfate flux datasets from ice cores with volcanological and, where applicable, petrological estimates of the $\mathrm{SO}_{2}$ mass emitted and historical records of large-magnitude volcanic eruptions. In the satellite era, volcanic emissions were primarily derived from remotely sensed observations. The database also includes the locations of each eruption and estimates of the maximum and minimum plume height. To estimate the mass of sulfur injected into the stratosphere, we take the estimated plume heights and compare to the climatological tropopause height at the latitude of each eruption.
If the maximum plume height is greater than the climatological tropopause, we assume that the $\mathrm{SO}_{2}$ emitted is in fact injected to the stratosphere. $\mathrm{SO}_{2}$ emissions from eruptions with maximum plume heights below the altitude of the local tropopause are thus ignored. Conversion from $\mathrm{SO}_{2}$ to sulfur mass is performed by multiplication by the ratio of molecular weights.

\subsubsection{Stratospheric aerosol optical depth}

The ICI reconstruction (Crowley and Unterman, 2013) contains estimates of zonal mean SAOD at $550 \mathrm{~nm}$ for four equal-area latitude bands over the period 800-2000. The reconstruction is based on a scaling of Greenland and Antarctic ice core composites to measured SAOD after the Mt. Pinatubo eruption of 1991. Here, we take the ICI SAOD estimates as they are provided and simply average the four equalarea bands into a global annual mean SAOD.

For the 1850-2000 period, the CMIP6 (version 2) stratospheric aerosol forcing reconstruction (ftp://iacftp.ethz.ch/ pub_read/luo/CMIP6/, Luo, 2016) has been constructed based on a combination of satellite- and ground-based optical measurements and aerosol model results (Arfeuille et al., 2014) using VSSI estimates from IVI2. While the dataset contains estimates of many physical and optical properties of the aerosols, we focus here on estimates of SAOD at $550 \mathrm{~nm}$. Aerosol extinction from the CMIP6 forcing files is integrated above the climatological tropopause at each latitude, and a simple area-weighted average is used to compute the global mean.

\section{Results}

\subsection{Ice sheet sulfate flux composites}

Greenland and Antarctic composite sulfate fluxes from eVolv2k are compared to composites from the IVI2 (Gao et al., 2008) and ICI (Crowley and Unterman, 2013) reconstructions in Fig. 1. For this comparison, we have focused on unambiguous matches between the three sets of composites between $\sim 1590$ and 2000, also including the 1257/8 Samalas signal, listed in Table S2. Flux composites for eVolv2k and the IVI2 datasets are plotted against the ICI reconstruction in Fig. 1.

The eVolv2k composite fluxes show rather close agreement with the values reported by ICI. Linear fits of the eVolv2k vs. ICI composite fluxes were computed using the OLS bisector method (Isobe et al., 1990), resulting in slopes of $0.89 \pm 0.14$ for Greenland and $0.87 \pm 0.12$ for Antarctica. On the other hand, the IVI2 flux values show a significant bias compared to ICI, with a slope of $1.33 \pm 0.14$ for Greenland and $1.30 \pm 0.26$ for Antarctica. Fits of the IVI2 fluxes against the eVolv2k fluxes (not shown) result in bias estimates of $1.49 \pm 0.21$ for Greenland and $1.50 \pm 0.28$ for Antarctica. 

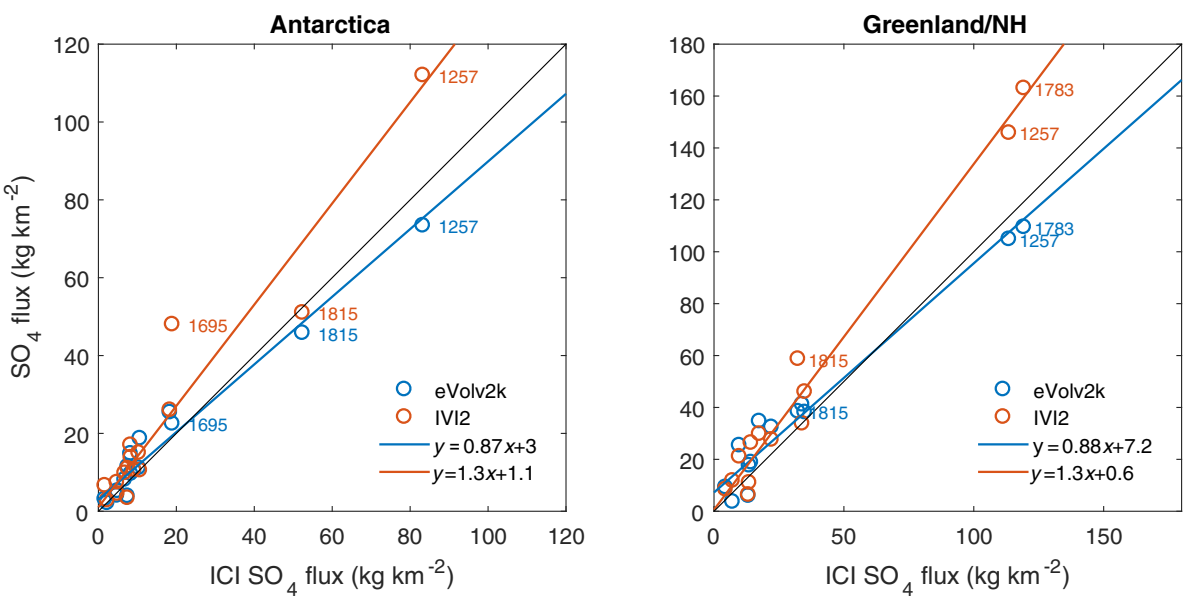

Figure 1. Composite sulfate fluxes derived from ice cores for (left) Antarctica and (right) Greenland (or NH). Values from the eVolv2k (this work) and IVI2 (Gao et al., 2008) reconstructions are plotted vs. composite values from the ICI reconstruction (Crowley and Unterman, 2013) for event matches defined in Table S2. Linear fits to the scatter plots are included, with best fit slopes and intercepts as included in the legends.
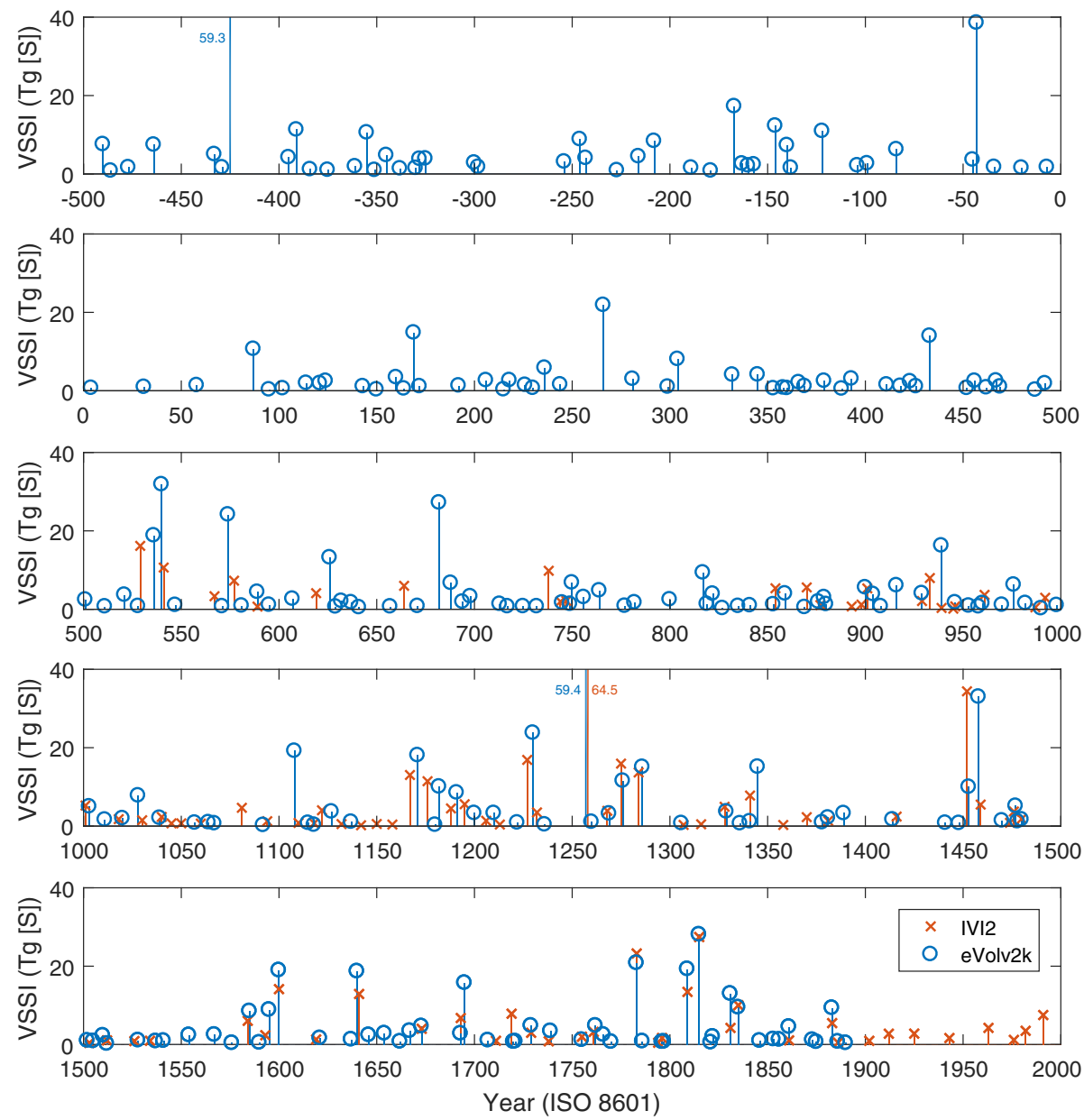

Figure 2. Volcanic stratospheric sulfur injection (VSSI) from the IVI2 and eVolv2k reconstructions. Values exceeding the $y$-axis limits are denoted as text. Years are shown using the ISO 8601 standard, which includes a year zero. 


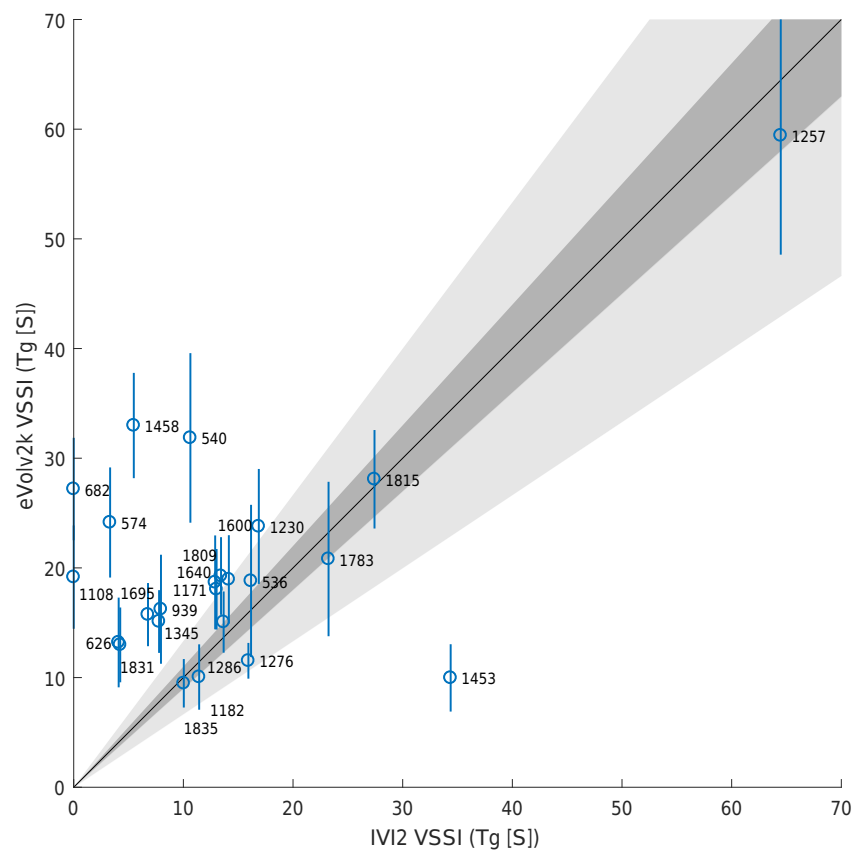

Figure 3. Scatter plot of matched eVolv2k vs. IVI2 VSSI estimates for events spanning 501-1900 CE with VSSI > 10 Tg [S]. Matches are defined in Table S3, and labels show the year of each event according to the eVolv $2 \mathrm{k}$ reconstruction. Vertical bars indicate the $1 \sigma$ uncertainty in the eVolv2k VSSI estimates. The $1: 1$ line is shown in black, with dark and light grey shading denoting the \pm 10 and $33 \%$ range around $1: 1$.

The apparent bias in the IVI2 fluxes compared to ICI and eVolv2 $\mathrm{k}$ is primarily due to the reported fluxes for the largest events. When the linear fits are repeated after removing the largest events $(1783,1258$, and 1815 for Greenland and 1258 and 1695 for Antarctica), the bias of the IVI2 fluxes compared to eVolv $2 \mathrm{k}$ reduces to $0.90 \pm 0.34$ for Greenland and $1.1 \pm 0.20$ for Antarctica. For Greenland, IVI2 used a large number of supplemental ice cores in the estimates for Tambora and Laki (Clausen and Hammer, 1988; MosleyThompson et al., 1993), which increased the composite estimates for these events significantly compared to values originally reported using only the long-term ice core records (Gao et al., 2006). Over Antarctica, the large IVI2 composite flux for 1257 is likely a result of the very strong flux recorded by the SP01 ice core from the South Pole (Budner and ColeDai, 2003), which was not reproduced by another ice core record from the same site (SP04, Ferris et al., 2011) and consequently was not included in the AVS-2k composite ( $\mathrm{Sigl}$ et al., 2014).

\subsection{Volcanic stratospheric sulfur injection}

The eVolv2k global VSSI time series is shown in Fig. 2 in comparison to the values from the IVI2 reconstruction. Over the 1500-1900 time period, the two reconstructions are very similar in terms of the timing and magnitude of most events, including Tambora (1815) and Laki (1783). The eVolv2k VSSI estimates for Huyanaputia (1600), Parker (1640), and the unidentified eruption of 1809 are slightly larger than those of IVI2.

Within the 1000-1500 CE time period, the two reconstructions agree reasonably well in terms of the timing and magnitude of the great 1257 Samalas eruption and the eruptions of 1276 and 1286. A major difference between the reconstructions is the timing of the great mid-15th century eruption, which differs by 6 years. Before $\sim 1250 \mathrm{CE}$, there is a notable shift in the timing of events, reaching about 6 years, and most events are of a somewhat larger magnitude in the eVolv2k reconstruction. Between 500 and $1000 \mathrm{CE}$, there is very little correlation between the two reconstructions. The eVolv2k reconstruction contains strong VSSI events, including events at 540,574, 682, and $1108 \mathrm{CE}$, which are missing or largely underestimated in the IVI2 reconstruction. Of particular note, the eVolv2k reconstruction includes a sequence of very large eruptions in the sixth century, including a $\mathrm{NH}$ extratropical eruption in $536 \mathrm{CE}$ and tropical eruptions in 540 and $574 \mathrm{CE}$, which is consistent with timings inferred in earlier studies (Baillie, 2008; Baillie and McAneney, 2015; Toohey et al., 2016a) and confirmed by Sigl et al. (2015), with VSSI magnitudes $25-30 \%$ larger than estimated by Toohey et al. (2016a). The extension of VSSI estimates back to 500 BCE reveals two large events: a Samalas-magnitude injection in $426 \mathrm{BCE}$ and an event of $\sim 40 \mathrm{Tg}$ sulfur $(30 \%$ greater than Tambora) in $44 \mathrm{BCE}$.

Global VSSI magnitudes for the major events common to the eVolv2k and IVI2 datasets over the 500-1900 CE period are compared in more detail in Fig. 3. Major events were defined here as those with VSSI values greater than $10 \mathrm{Tg}[\mathrm{S}]$. Lists were compiled of major events from both datasets, and matches between the two datasets were found based on coincidence in time (Table S3), allowing for a drift in time in the early portion of the overlap period consistent with recent updates to the ice core dating (Sigl et al., 2015). If no match was found for a strong event in one dataset, a VSSI value of 0 was specified for the other dataset.

VSSI estimates from eVolv2k and IVI2 for many of the largest events, including the 1257, 1783, and 1815 events, agree to $\sim 10 \%$ (Fig. 3). This agreement reflects compensation between changes in the ice core sulfate flux composites used in the two reconstructions (see Fig. 1) and the $33 \%$ increase in effective transfer function used in the construction of eVolv2k. If the 1452 event from IVI2 was matched to the 1458 event of eVolv2k, they would also agree to within $10 \%$, yet this agreement is largely coincidental, since the IVI2 value is based on combining values from two likely disparate events in 1452 and 1458 (Cole-Dai et al., 2013; Plummer et al., 2012; Sigl et al., 2013). A handful of other smaller events agree between the two datasets to within $33 \%$, including events in 536, 1182, 1276, 1286, and 1835. Five events $(1230,1171,1600,1640$, and $1809 \mathrm{CE})$ have VSSI values 

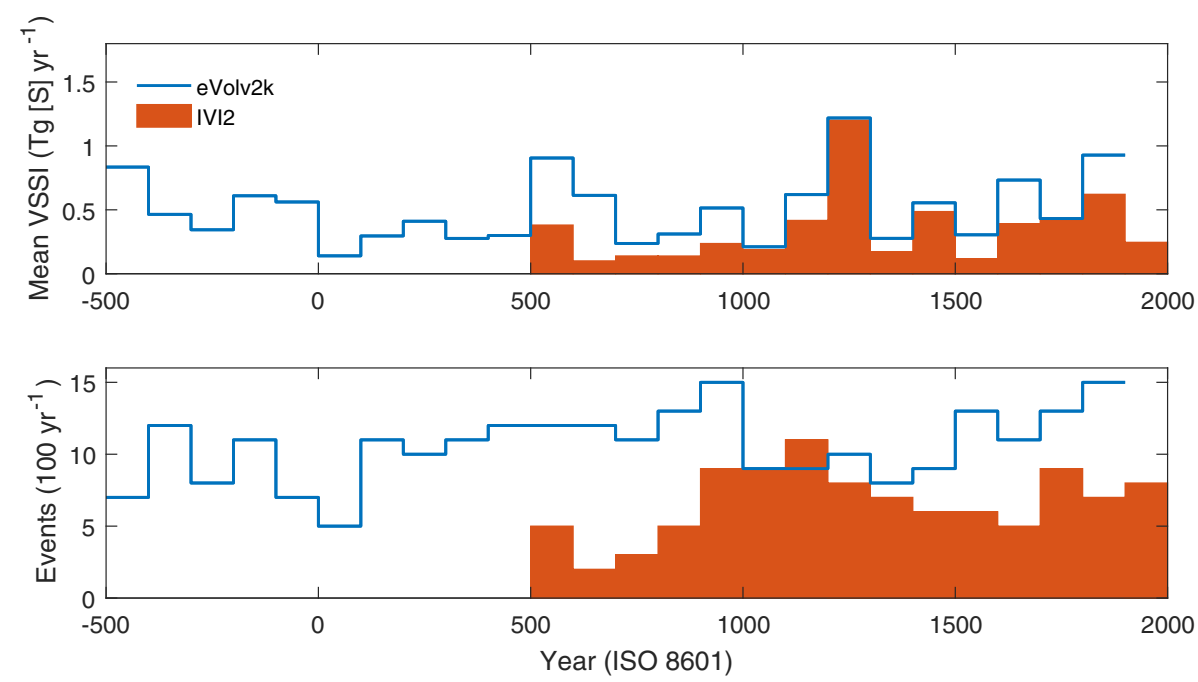

Figure 4. (a) Centennial mean volcanic stratospheric sulfur injections (VSSI) from the IVI2 and eVolv2k reconstructions. (b) The number of volcanic events per century included in the eVolv2k and IVI2 reconstructions. Years are shown using the ISO 8601 standard, which includes a year zero.
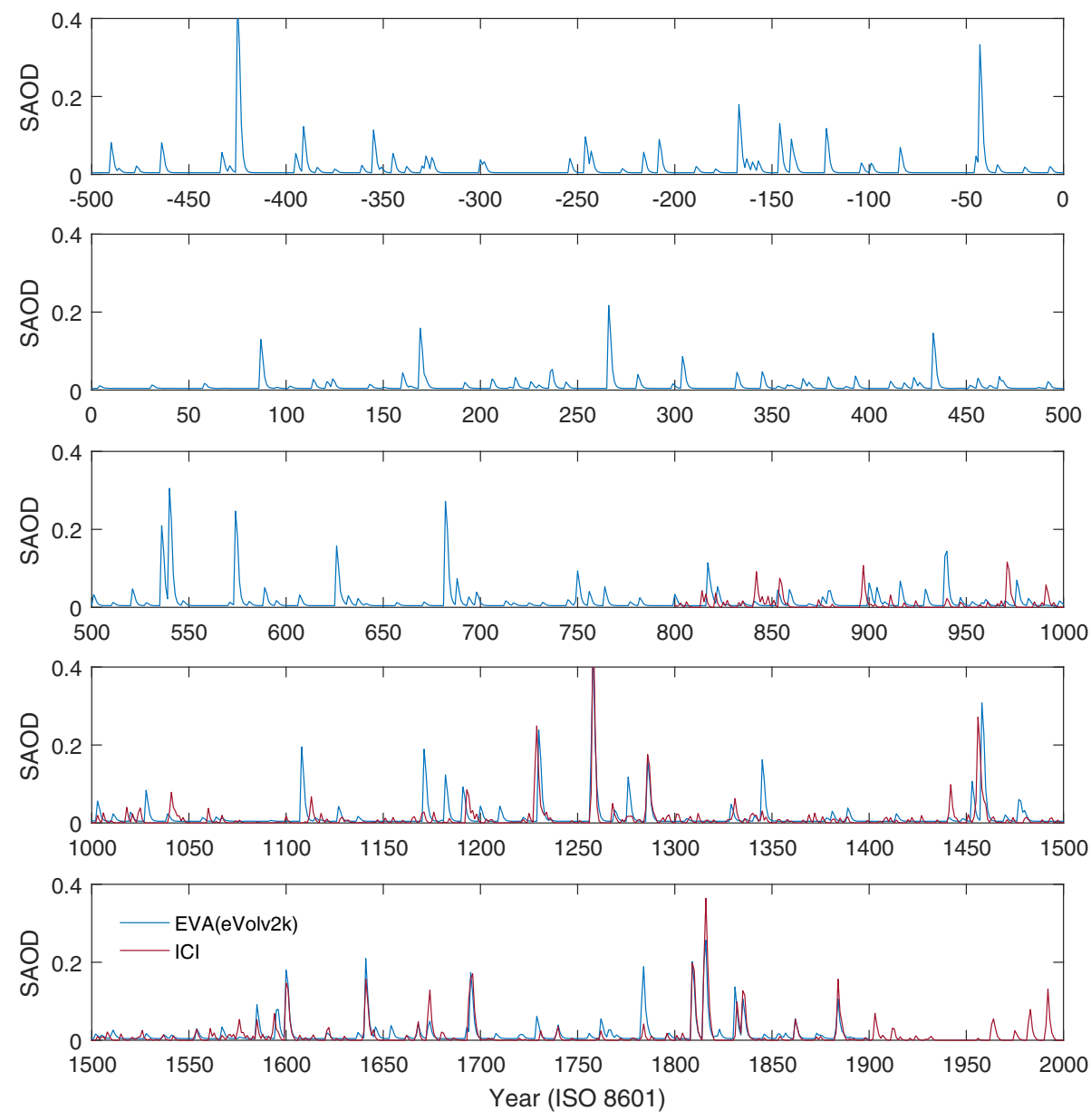

Figure 5. Global mean annual mean stratospheric aerosol optical depth (SAOD) from the EVA(eVolv2k) and ICI reconstructions. Years are shown using the ISO 8601 standard, which includes a year zero. 


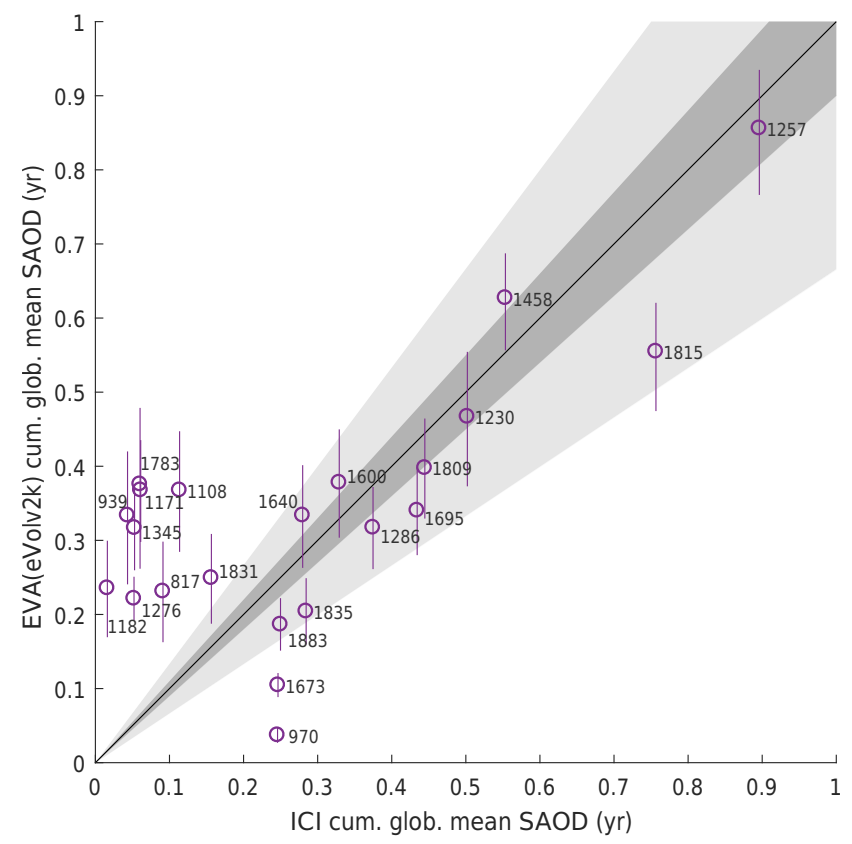

Figure 6. Scatter plot of matched EVA(eVolv2k) vs. ICI estimates of 3-year cumulative global mean SAOD for events with values greater than 0.2. Matches are defined in Table S4. Labels show the eVolv $2 \mathrm{k}$ date of each event. Vertical bars indicate the $1 \sigma$ uncertainty in the EVA(eVolv2k) SAOD estimates. The $1: 1$ line is shown in black, with dark and light grey shading denoting the \pm 10 and $33 \%$ range around $1: 1$.

$33-40 \%$ larger in eVolv2k, representing the impact of the increased transfer functions on similar ice sheet composite fluxes. Around 10 events in eVolv2k have VSSI values significantly more than $33 \%$ larger than in the IVI2 reconstruction. Some of these events appear to be missing $(682,1108)$ or significantly underestimated $(540,574,626,939)$ in IVI2, likely due to a lack of synchronisation of the underlying ice core records. Relative increases of 33-60\% for other events (e.g. 1695 and 1831) reflect in part the identification of bipolar ice core signals and therefore the assignment of a tropical source for the eruption rather than an extratropical source assumed by IVI2.

Estimated random uncertainties in the VSSI values are displayed as vertical error bars in Fig. 3. Uncertainties for VSSI greater than $20 \mathrm{Tg}[\mathrm{S}]$ range from about 15 to $30 \%$ (Fig. S6). Due to relatively uniform sulfate fluxes over the Greenland and Antarctica ice core samples, VSSI estimates for the 1458 event and Tambora (1815) are among the most tightly constrained, with uncertainties of 15 and $16 \%$, respectively. The VSSI uncertainty for Samalas (1257) is $18 \%$, while the large events of $540 \mathrm{CE}$ and Laki (1783) have larger uncertainties, with estimated values of 24 and $34 \%$, respectively.

Centennial-scale variations in the eVolv2k and IVI2 VSSI reconstructions are shown in Fig. 4. Centennial average VSSI values (Fig. 4a) are dominated by the largest events: max- imum centennial averages occur in the 6th, 13th, and 19th centuries, which together contain 7 of the top 20 VSSI events of the eVolv2k dataset (Table 2). Minimum centennial mean VSSI is found during a "Roman Quiet Period" in the first century $\mathrm{CE}$, with a mean value of about $0.1 \mathrm{Tg}[\mathrm{S}] \mathrm{yr}^{-1}$, a full order of magnitude less than that of the maximum century (1200-1300 CE) and less than one-third of the long-term average. The century with the second lowest level of volcanism is 1000-1100 CE, corresponding with the "Medieval Quiet Period" (Bradley et al., 2016). Compared to IVI2, eVolv2k VSSI averages are larger for all centuries, with large differences occurring near the beginning of the period of overlap (e.g. the 6th, 7th, and 10th centuries) but also in the more recent centuries (e.g. 17th and 19th centuries). The eVolv2k reconstruction also contains generally more events than that of IVI2 (Fig. 4b), with an average of 10.6 events per century compared to 6.7 events per century in the IVI2 dataset. The centennial event frequency in eVolv $2 \mathrm{k}$ is also slightly more uniform with time, with a coefficient of variation of 0.24 , compared to 0.37 for IVI2. The largest increase in the number of events identified in the eVolv2k database compared to IVI2 is in the years $500-1000 \mathrm{CE}$ when eVolv2k includes 12.0 events per century compared to 5.5 events per century in IVI2.

\subsection{Stratospheric aerosol optical depth}

Time series of global mean SAOD from the EVA(eVolv2k) and ICI reconstructions are shown in Fig. 5 (zonal mean SAOD is shown for the full EVA(eVolv2k) reconstruction in Fig. S7). Similar to the VSSI comparisons, the timing and magnitudes of major SAOD perturbations in the two reconstructions are similar from 1250 to $1900 \mathrm{CE}$ and significantly different before around $1200 \mathrm{CE}$.

A comparison of the magnitude of matched strong events in the eVolv2k and ICI SAOD reconstructions (Table S4) is shown in Fig. 6. Maximum values of 3-year cumulative SAOD are compared to reduce differences due to the different temporal evolutions or assumed starting dates of events in the two reconstructions. Most of the largest SAOD events agree to within $33 \%$, including the 1230, 1257, 1458, 1600, 1640,1809 , and 1815 events. Tambora is a notable case, with EVA(eVolv2k) cumulative SAOD approximately $25 \%$ smaller than that of the ICI reconstruction. Laki (1783) and other $\mathrm{NH}$ extratropical eruptions (e.g. 939, 1182) have much larger SAOD in the eVolv2k reconstruction, a result of not applying a correction for effusive tropospheric eruptions as done in the ICI. Other apparent outliers can be understood to result from the inclusion of the then unsynchronised Plateau Remote and Taylor Dome ice cores in the ICI reconstruction. Contributing 40-50\% weight to the mean Antarctic $\mathrm{SO}_{4}$ flux composite before $1200 \mathrm{CE}$, the unsynchronised series from these two ice cores generally reduced the mean sulfate values for real volcanic events while falsely generating apparent volcanic signals not observed by those ice cores that had 


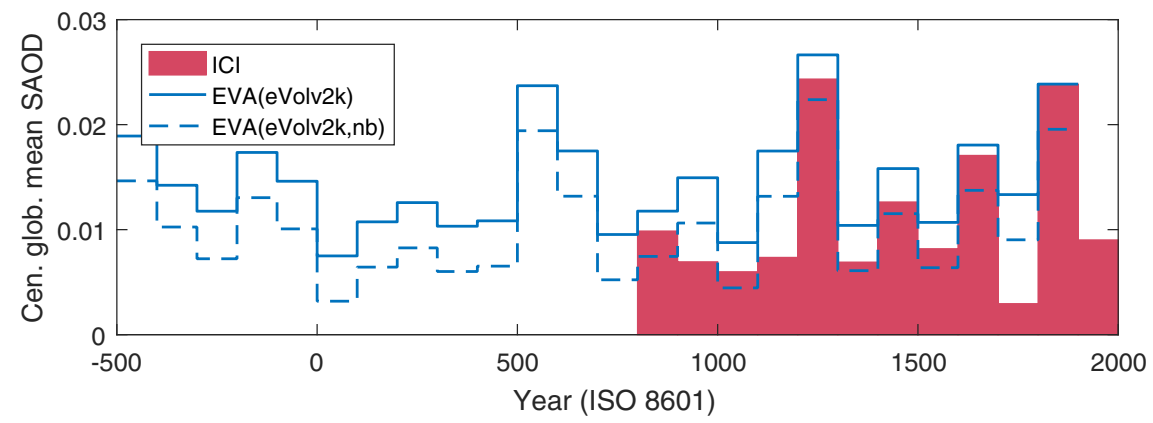

Figure 7. Centennial global mean SAOD from the ICI and EVA(eVolv2k) reconstructions. A version of the EVA reconstruction which includes no background sulfur injection, EVA(eVolv2k, nb), is shown by the dashed line.

Table 2. The top 20 eruptions from the past 2500 years in terms of volcanic stratospheric sulfur injection (VSSI) in the eVolv2k reconstruction. Matched stratospheric sulfur injections from the IVI2 reconstruction (Gao et al., 2008), when available, are included for comparison.

\begin{tabular}{lrrrr}
\hline & \multicolumn{3}{c}{ IVI2 } \\
\cline { 2 - 5 } Eruption & Year (BCE/CE) & VSSI (Tg [S]) & Year & VSSI (Tg [S]) \\
\hline Samalas & 1257 & 59.4 & 1258 & 64.5 \\
Unidentified & -426 & 59.3 & - & - \\
Unidentified & -44 & 38.6 & - & - \\
Unidentified & 1458 & 33.0 & $1459 / 1452$ & $5.5 / 34.4$ \\
Unidentified & 540 & 31.8 & 541 & 10.6 \\
Tambora & 1815 & 28.1 & 1815 & 27.0 \\
Unidentified & 682 & 27.2 & No match & 0 \\
Unidentified & 574 & 24.1 & 567 & 3.3 \\
Unidentified & 1230 & 23.8 & 1227 & 16.9 \\
Unidentified & 266 & 21.9 & - & - \\
Grímsvötn (Laki) & 1783 & 20.8 & 1783 & 23.2 \\
Unidentified & 1809 & 19.3 & 1809 & 13.5 \\
Unidentified & 1108 & 19.2 & No match & 0 \\
Huaynaputina & 1600 & 19.0 & 1600 & 14.1 \\
Unidentified & 536 & 18.8 & 529 & 16.2 \\
Parker & 1640 & 18.7 & 1641 & 12.9 \\
Unidentified & 1171 & 18.0 & 1167 & 13.0 \\
Unidentified & -168 & 17.2 & - & - \\
Katla (Eldgjá) & 939 & 16.2 & 933 & 8.0 \\
Unidentified & 433 & 15.9 & - & - \\
\hline
\end{tabular}

been correctly synchronised (see Sigl et al., 2014, SOM for details).

Centennial mean SAOD estimates (Fig. 7) show larger mean values for EVA(eVolv2k) compared to ICI in all centuries. This difference is almost entirely due to the inclusion of a non-zero background SAOD in the EVA(eVolv2k) reconstruction: an alternate version with no background sulfur injection, EVA(eVolv2k, nb), shows closer agreement with the centennial-scale variation of ICI. The much stronger mean SAOD in the EVA(eVolv2k) reconstruction in the 18th century can be understood to result from the much larger estimate for Laki (1783). The stronger estimated mean SAOD for the 800-1200 time period is due to the identification of a number of events that are missing or have much smaller estimates in the ICI reconstruction.

The 1850-1900 period is included in the long-term EVA(eVolv2k) and ICI SAOD reconstructions as well as the CMIP6 historical (1850-2015) period forcing reconstruction, which is based on a mixture of observations and aerosol model results using VSSI estimates of the IVI2 reconstruction (Arfeuille et al., 2014). Over the overlapping 1850-1900 period, the EVA(eVolv2k) and CMIP6 reconstructions agree to within $20 \%$ in their estimation of the cumulative global mean SAOD for the 1883 Krakatau eruption (Fig. 8). In contrast, the ICI reconstruction's cumulative SAOD for Krakatau is $25 \%$ larger than that of the EVA(eVolv2k) and CMIP6 estimates. Based on matching Greenland and Antarctic sul- 

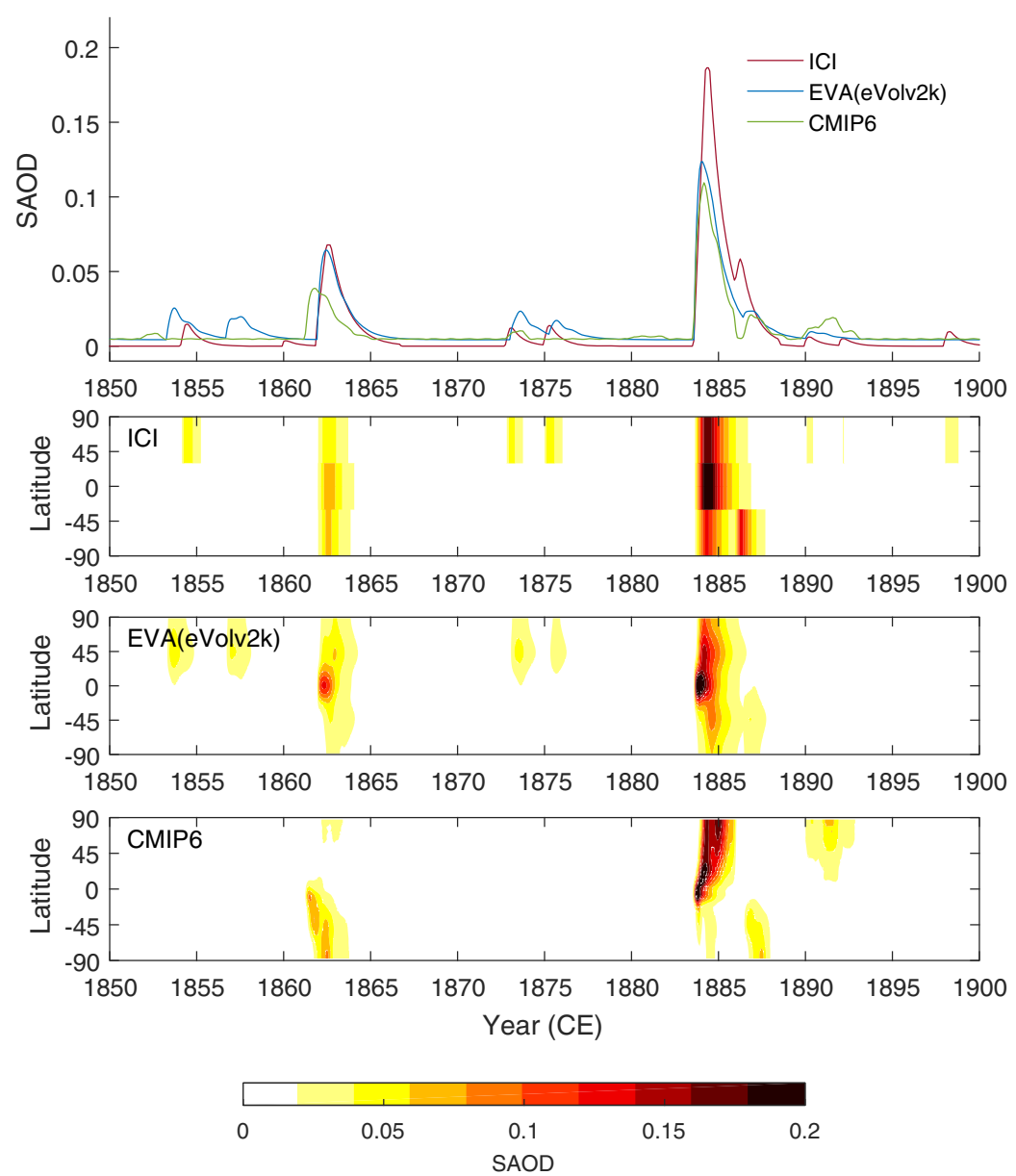

Figure 8. Global mean SAOD (top) from the ICI, EVA(eVolv2k), and CMIP6 version 2 reconstructions for the 1850-1900 time period of overlap. Zonal mean SAOD (bottom) from the three reconstructions as labelled for the same time period.

Table 3. Long-term average annual VSSI estimates from different reconstructions.

\begin{tabular}{lccc}
\hline Time period & $\begin{array}{c}\text { eVolv2k VSSI } \\
\left(\mathrm{Tg}[\mathrm{S}] \mathrm{yr}^{-1}\right)\end{array}$ & $\begin{array}{c}\text { IVI2 VSSI } \\
\left(\mathrm{Tg}[\mathrm{S}] \mathrm{yr}^{-1}\right)\end{array}$ & $\begin{array}{c}\text { VolcEESM VSSI } \\
\left(\mathrm{Tg}[\mathrm{S}] \mathrm{yr}^{-1}\right)\end{array}$ \\
\hline$-500-1900$ & 0.49 & - & - \\
$501-1900$ & 0.54 & 0.35 & - \\
$1901-2000$ & - & 0.25 & 0.37 \\
\hline
\end{tabular}

fate signals, eVolv2k and ICI attribute a signal in 1862 to a tropical eruption, and the reconstructed SAOD in both reconstructions is roughly twice as large as that of CMIP6, in which it is assumed to be extratropical. Figure 8 also shows the consistency in the background SAOD reconstructed in the eVolv2k and CMIP6 datasets in contrast to the zero-level background assumed in the ICI reconstruction. Zonal mean SAOD from the ICI, EVA(eVolv2k), and CMIP6 reconstructions is shown in Fig. 8 over the same 1850-1900 period. The EVA(eVolv2k) reconstruction includes a smooth latitudinal structure based on the observed evolution of aerosol after the 1991 Pinatubo eruption (Toohey et al., 2016b), avoiding the strong localised gradients in SAOD present in the four-band structure of the ICI reconstruction. As in the ICI reconstruction, the EVA(eVolv2k) SAOD also reproduces hemispheric asymmetry in the SAOD based on the ratio of ice core fluxes from both hemispheres, avoiding potential biases related to purely simulated aerosol transport, which for example appear to be creating a strong NH bias in the CMIP6 SAOD representation of the Krakatau eruption. 
Table 4. Long-term average SAOD from different reconstructions. Results are listed for both the standard EVA(eVolv2k) SAOD reconstruction and a version with no background stratospheric sulfur injection denoted EVA(eVolv2k, nb).

\begin{tabular}{lcccc}
\hline Time period & $\begin{array}{c}\text { EVA(eVolv2k) } \\
\text { SAOD }\end{array}$ & $\begin{array}{c}\text { EVA(eVolv2k, nb) } \\
\text { SAOD }\end{array}$ & $\begin{array}{c}\text { ICI } \\
\text { SAOD }\end{array}$ & $\begin{array}{c}\text { CMIP6 } \\
\text { SAOD }\end{array}$ \\
\hline$-500-1900$ & 0.014 & 0.010 & - & - \\
$801-1900$ & 0.015 & 0.011 & 0.011 & - \\
$1901-2000$ & - & - & 0.009 & 0.012 \\
\hline
\end{tabular}

\subsection{A long-term context to 20th century volcanic forcing}

Long-term mean VSSI and SAOD estimates from eVolv2k and other reconstructions are listed in Tables 3 and 4 for different time periods, allowing for a comparison with recent estimates for the 20th century.

The overall long-term (500 BCE-1900 CE) mean VSSI from the eVolv2 $\mathrm{k}$ reconstruction is $0.49 \mathrm{Tg}^{\mathrm{S}}[\mathrm{S}] \mathrm{yr}^{-1}$. This estimate is consistent with the estimate from Pyle et al. (1996) based on satellite observations and compiled estimates of global eruption frequencies over the last $\sim 200$ years, although their estimate discounted the impact of the largest eruptions. A mean VSSI rate of $0.49 \mathrm{Tg}[\mathrm{S}] \mathrm{yr}^{-1}$ is about 2.5 times larger than the best estimate of the yearly natural "background" input of sulfur to the stratosphere by the crosstropopause transport of aerosols and their precursors (Sheng et al., 2015).

Over the common period of overlap (500-1900), the eVolv2k VSSI injection mean is $\sim 50 \%$ larger than that of the IVI2 reconstruction. As discussed earlier, this is due to the identification of more moderate eruptions, especially early in the time period, and an enhancement of the estimated magnitude of a number of moderate events.

The long-term (500 BCE-1900 CE) mean SAOD in $\mathrm{EVA}(\mathrm{eVolv} 2 \mathrm{k})$ is 0.014 . A version with no background sulfur injection produces a mean of 0.010 ; therefore, major volcanic sulfur injections contribute approximately two-thirds of the long-term mean SAOD. The EVA(eVolv2k) version with no background injection shows very close agreement with the long-term mean of the ICI SAOD reconstruction: the larger mean SAOD in eVolv2k compared to ICI can thus be understood to be the result of the background injection. The CMIP6 20th century mean SAOD is about $14 \%$ lower than the long-term EVA(eVolv2k) reconstruction. The fact that the difference between 20th century and long-term mean SAOD is smaller than that for VSSI is expected due to the inclusion of the constant background sulfur injection in the SAOD reconstruction.

\section{Data availability}

The eVolv2k volcanic stratospheric sulfur injection and EVA(eVolv2k) stratospheric aerosol optical depth datasets described herein are available through the World Data Center for Climate in netCDF format
(https://doi.org/10.1594/WDCC/eVolv2k_v2; Toohey and Sigl, 2017).

Comprehensive stratospheric aerosol optical properties useful for climate model simulations are readily obtained through the use of the EVA forcing generator (Toohey et al., 2016) and eVolv2k dataset. Output from EVA includes aerosol extinction, scattering asymmetry factor, and single scattering albedo as a function of time, latitude, height, and wavelength, which is consistent in format with the volcanic radiative forcing reconstruction recommended for use in the CMIP6 historical experiment. The necessary code modules, data, and instructions for their use are available for download through the Paleoclimate Modelling Intercomparison Project Phase 4 Last Millennium experimental design webpage (https://pmip4.lsce.ipsl.fr/doku.php/exp_design:lm).

\section{Conclusions and discussion}

This paper presents a new reconstruction of the climatic influence of major volcanic eruptions over the time span from $500 \mathrm{BCE}$ to $1900 \mathrm{CE}$. The eVolv2k reconstructions of volcanic VSSI and SAOD presented here represent, first and foremost, the results of improved dating, resolution, and synchronisation of ice core sulfate records from Antarctica and Greenland (Sigl et al., 2014, 2015). Given the improvements in methodologies used to date and synchronise ice core records - including automated synchronising and absolute dating through the matching of signatures of cosmogenic isotopes in ice cores and tree rings in the eighth century (Sigl et al., 2015) - the eVolv2k reconstruction can be confidently assumed to be a more accurate estimate of volcanic forcing compared to prior reconstructions, particularly for time periods before $\sim 1250 \mathrm{CE}$. This assertion is supported by strong correlation between the newly compiled volcanic ice core records and instances of sudden large-scale cooling from dendrochronological climate reconstructions (Sigl et al., 2015).

The eVolv2k reconstruction provides the input data for climate model simulations which aim to include external climate forcing agents as far back in time as 500 BCE. Volcanic stratospheric sulfur injection (VSSI) estimates can be directly ingested by suitable aerosol climate models. Alternatively, the EVA forcing generator (Toohey et al., 2016b) can be used to produce stratospheric aerosol optical properties, 
including the stratospheric aerosol optical depth (SAOD) based on the VSSI record. Aerosol optical properties can then be used as boundary conditions for model simulations. The eVolv2k reconstruction is the recommended volcanic forcing for transient simulations within the Paleoclimate Modelling Intercomparison Project (PMIP; Jungclaus et al., 2016) and therefore represents an update to the reconstructions most often used in prior palaeo-simulations, including the IVI2 (Gao et al., 2008) and ICI (Crowley and Unterman, 2013) forcing datasets.

The eVolv2k VSSI estimates and the related SAOD perturbations produced via the EVA forcing generator show broad agreement with the IVI2 and ICI reconstructions over the 1250-1900 period in terms of the magnitudes of the largest volcanic events. For VSSI, agreement between eVolv2k and IVI2 is the product of compensatory differences, including generally smaller ice core flux estimates and a larger effective transfer function used to scale ice core sulfate fluxes into VSSI estimates. For the SAOD reconstructions, agreement between the EVA(eVolv2k) and ICI reconstructions reflects relative consistency in the ice core composites (after $\sim 1250$ ) constructed in both efforts and a related methodology, wherein observations following the 1991 Pinatubo eruption are used to define the scaling from ice core sulfate to SAOD. Before $1250 \mathrm{CE}$, the eVolv2k VSSI and SAOD reconstructions include a number of events which are comparatively underestimated or completely missing in prior reconstructions. These updated estimates promise improvements in the attribution of forced and unforced climate variability before $1250 \mathrm{CE}$.

In general, estimates of long-term mean VSSI and SAOD in eVolv2k are larger than prior reconstructions. For VSSI, this reflects an increase in the number of identified events and an increase in the estimated magnitude for a number of moderate to strong events. The relative increase in long-term mean SAOD compared to prior work is primarily due to the inclusion of a non-zero minimum (or background) SAOD, which is consistent with the minimum in stratospheric SAOD observed by satellite sensors around the year 2000 CE. The long-term estimates of VSSI and SAOD evolution give context to the best current estimates of 20th century volcanic forcing. An independent estimate of 20th century mean VSSI is about $25 \%$ smaller than the long-term eVolv $2 \mathrm{k}$ mean. Assuming stationarity of global eruption frequencies, it is therefore more likely than not that the 21 st century mean volcanic forcing will be greater than that of the 20th century.

For the first time, the eVolv2k reconstruction provides estimates of the uncertainty in volcanic VSSI estimates based on estimated uncertainty in the ice core sulfate composites and the error inherent in using ice sheet average fluxes as a proxy for the full hemispheric sulfate deposition (and therefore the hemispheric atmospheric sulfate loading). These error estimates depend on the number of ice cores used in the composite and the degree of variation seen between the ice cores. For most of the largest volcanic events, the estimated uncertainty is around $20-30 \%$, while for smaller events the estimated error reaches values of $>50 \%$. Systematic errors are also significant, representing the possibility that VSSI or SAOD estimates are biased in the long-term average. The construction of transfer functions from the NWT of the 1950s and 1960s and from the single data point of the 1991 Pinatubo eruption carries significant uncertainties regarding the injection magnitudes and injection heights. Observational estimates of the VSSI of Pinatubo have uncertainties of $\sim 20 \%$ (Guo et al., 2004), and recent modelling studies have argued for a VSSI from Pinatubo half that of the usual estimates (e.g. Dhomse et al., 2014). An important uncertainty in the reconstruction of volcanic forcing stems from the inability to differentiate between ice core sulfate from vast, stratospheric sulfate clouds and that from relatively local effusive eruptions. Icelandic eruptions with large effusive emissions, like Laki or the 2014-2015 Holuhraun eruption (Schmidt et al., 2015), could theoretically lead to large sulfate fluxes to the Greenland ice sheets with little to no significant stratospheric injection. VSSI and SAOD estimates then based on the raw Greenland sulfate records would produce large overestimates of the global effects of the eruptions. This issue led Crowley and Unterman (2013) to mute the impact of Greenland sulfate fluxes for signals that could be attributed to Icelandic eruptions in the ICI reconstruction. On the other hand, the vertical distribution of the sulfur emissions by Laki are still under debate (Lanciki et al., 2012; Schmidt et al., 2012), and while it seems likely that the Greenland sulfate signal for Laki does contain some component related to tropospheric emissions, the proportion of tropospheric to stratospheric injections is very unclear. For these reasons, we have not implemented a correction to the VSSI estimates of Laki or other known or suspected Icelandic eruptions. Uncertainties in the scaling procedures used within the EVA forcing generator certainly add another level of uncertainty to the SAOD estimates: for example, uncertainty in the measured SAOD after Pinatubo translates directly into systematic uncertainty in the SAOD estimated by EVA.

Future work should be able to further refine the estimates of VSSI and SAOD presented here. First, a larger network of high-quality ice core sulfate records from Greenland should reduce random errors in the composite flux due to limited sampling. Reducing uncertainty in the transfer functions used to link atmospheric sulfate content and ice core sulfate fluxes would greatly improve estimates of volcanic forcing. Studies with atmospheric models show some promise (Gao et al., 2007; Toohey et al., 2013; Marshall et al., 2017), but inter-model differences in stratospheric sulfate evolution highlight substantial uncertainties in the physical processes controlling aerosol growth and transport (Zanchettin et al., 2016). Emerging techniques to differentiate sulfur from tropospheric vs. stratospheric origin (e.g. Lanciki et al., 2012) offer potential strategies for reducing uncertainties in future volcanic forcing reconstructions. Finally, the continued extension of ice core volcanic records to the 
present should soon provide important information, since anthropogenic sulfate flux over Greenland - contaminated over much of the 20th century by anthropogenic sulfur emissions - has now almost reached pre-industrial levels, allowing for the detection of moderate volcanic eruptions in Greenland. 


\section{Appendix A: Greenland ice core flux uncertainty analysis}

Simple statistical models can often be useful tools for estimating biases and errors in measured datasets (Dunn, 1989; Toohey and Strong, 2007). Given the apparent lack of bias between the three Greenland ice core sulfate records used in the eVolv2k Greenland composite (Fig. S4), we assume here a simple model, wherein the sulfate flux recorded by a single ice core $\left(x_{i}\right)$ and its relationship with the ice-sheet-wide average flux $\left(\tau_{i}\right)$ can be written as

$x_{i}=\tau_{i}+\delta_{i} \tau_{i}$,

where $\delta_{i}$ is assumed to be a zero-mean, normally distributed random variable with error variance $\sigma_{\delta}^{2}$. We assume here that the measured values $x_{i}$ have constant relative errors, and thus the total error $\left(\delta_{i} \tau_{i}\right)$ is proportional to the ice sheet average $\tau_{i}$.

Further measurements, e.g. from other sites on the ice sheet, can be similarly modelled:

$y_{i}=\tau_{i}+\varepsilon_{i} \tau_{i}$,

$z_{i}=\tau_{i}+\gamma_{i} \tau_{i}$.

Under this model, the variance of each measurement set can be written as

$\sigma_{x}^{2}=\sigma_{\tau}^{2}+\mu^{2} \sigma_{\delta}^{2}+\sigma_{\delta}^{2} \sigma_{\tau}^{2}$,

where $\mu$ is the expected value of $\tau_{i}$. The covariance between two measurements sets - assuming no correlation between the random errors - is given by

$\sigma_{x y}=\sigma_{\tau}^{2}$.

Solving Eq. (A4) for $\sigma_{\delta}^{2}$ and replacing the population variances $\sigma_{x}^{2}$ and $\sigma_{x y}$ with the sample variances $s_{x x}$ and $s_{x y}$ produces an expression for the estimated error variance $\sigma_{\delta}^{2}$ :

$\hat{\sigma}_{\delta}^{2}=\frac{s_{x x}-s_{x y}}{\mu^{2}-s_{x y}}$.
Equivalent expressions can be constructed for $\hat{\sigma}_{\epsilon}^{2}$ and $\hat{\sigma}_{\gamma}^{2}$. The covariance terms $s_{x y}, s_{x z}$, and $s_{y z}$ all act as estimates of the true ice sheet average variance $\sigma_{\tau}^{2}$ but will give different values with finite sample sizes. A conservative estimate for each of the measurement error variances is produced by using the minimum values from the three covariances, which we have done here. Similarly, we use the minimum value from the means of $x, y$, and $z$ as the conservative estimate of $\mu$.

We used Eq. (A6) (and the equivalent expressions for $\hat{\sigma}_{\epsilon}^{2}$ and $\hat{\sigma}_{\gamma}^{2}$ ) to estimate error variances for the Greenland NEEM, NGRIP, and GISP2 datasets based on volcanic events with sulfate flux values in all three cores. Since variances and covariances can be very sensitive to the largest values within their input fields, we computed the error variances iteratively, beginning with the full dataset and removing the event with the largest mean flux value over the three cores for each iteration. The resulting error variance estimates fluctuate considerably after the removal of the first few largest values and then reach relatively stable values (Fig. S5). We took the mean values for each error estimate over the $n$ range of 3 11 , over which the estimates are rather stable, but utilise almost the full dataset. This analysis resulted in estimates for $1 \sigma$ errors of $46 \%$ for NEEM, $45 \%$ for NGRIP, and $33 \%$ for GISP2.

For any composite flux record calculated as the mean of $n$ individual flux records with uncertainties $\sigma_{i}$, we compute the composite uncertainty $\sigma_{n}$ according to standard rules of error propagation, i.e.

$\sigma_{n}=\frac{1}{n} \sqrt{\sum \sigma_{i}^{2}}$ 


\section{The Supplement related to this article is available online at https://doi.org/10.5194/essd-9-809-2017-supplement.}

Competing interests. The authors declare that they have no conflict of interest.

Acknowledgements. The authors thank reviewers Raymond Bradley and Chaochao Gao for their helpful comments. Matthew Toohey acknowledges support by the Deutsche Forschungsgemeinschaft (DFG) in the framework of the priority programme "Antarctic Research with comparative investigations in Arctic ice areas" through grant TO 967/1-1. Computations were carried out at the German Climate Computing Centre (DKRZ). This work benefitted greatly as a result of the authors' participation in the Past Global Changes (PAGES) Volcanic Impacts on Climate and Society (VICS) working group.

The article processing charges for this open-access publication were covered by a Research

Centre of the Helmholtz Association.

Edited by: David Carlson

Reviewed by: Chaochao Gao and Raymond Bradley

\section{References}

Abbott, P. M. and Davies, S. M.: Volcanism and the Greenland ice-cores: the tephra record, Earth-Sci. Rev., 115, 173-191, https://doi.org/10.1016/j.earscirev.2012.09.001, 2012.

Adolphi, F. and Muscheler, R.: Synchronizing the Greenland ice core and radiocarbon timescales over the Holocene - Bayesian wiggle-matching of cosmogenic radionuclide records, Clim. Past, 12, 15-30, https://doi.org/10.5194/cp-12-15-2016, 2016.

Ammann, C. M., Meehl, G. A., Washington, W. M., and Zender, C. S.: A monthly and latitudinally varying volcanic forcing dataset in simulations of 20th century climate, Geophys. Res. Lett., 30, 59-1, https://doi.org/10.1029/2003GL016875, 2003.

Arfeuille, F., Weisenstein, D., Mack, H., Rozanov, E., Peter, T., and Brönnimann, S.: Volcanic forcing for climate modeling: a new microphysics-based data set covering years 1600 present, Clim. Past, 10, 359-375, https://doi.org/10.5194/cp-10359-2014, 2014.

Baillie, M. G. L.: Proposed re-dating of the European ice core chronology by seven years prior to the 7th century AD, Geophys. Res. Lett., 35, L15813, https://doi.org/10.1029/2008GL034755, 2008.

Baillie, M. G. L. and McAneney, J.: Tree ring effects and ice core acidities clarify the volcanic record of the first millennium, Clim. Past, 11, 105-114, https://doi.org/10.5194/cp-11105-2015, 2015.

Bluth, G. J. S., Rose, W. I., Sprod, I. E., and Krueger, A. J.: Stratospheric loading of sulfur from explosive volcanic eruptions, J. Geol., 105, 671-684, https://doi.org/10.1086/515972, 1997.
Bradley, R. S., Wanner, H., and Diaz, H. F.: The medieval quiet period, The Holocene, 26, 990-993, https://doi.org/10.1177/0959683615622552, 2016.

Budner, D. and Cole-Dai, J.: The number and magnitude of large explosive volcanic eruptions between 904 and 1865 A.D.: Quantitative evidence from a new South Pole ice core, American Geophysical Union, 165-176, 2003.

Carn, S. A., Clarisse, L., and Prata, A. J.: Multidecadal satellite measurements of global volcanic degassing, J. Volcanol. Geoth. Res., 311, 99-134, https://doi.org/10.1016/j.jvolgeores.2016.01.002, 2016.

Clausen, H. B. and Hammer, C. U.: The Laki and Tambora eruptions as revealed in Greenland ice cores from 11 locations, Ann. Glaciol., 10, 16-22, 1988.

Clausen, H. B., Hammer, C. U., Hvidberg, C. S., Dahl-Jensen, D., Steffensen, J. P., Kipfstuhl, J., and Legrand, M.: A comparison of the volcanic records over the past 4000 years from the Greenland Ice Core Project and Dye 3 Greenland ice cores, J. Geophys. Res.-Oceans, 102, 26707-26723, https://doi.org/10.1029/97JC00587, 1997.

Clerbaux, C., Coheur, P.-F., Clarisse, L., Hadji-Lazaro, J., Hurtmans, D., Turquety, S., Bowman, K., Worden, H., and Carn, S. A.: Measurements of $\mathrm{SO}_{2}$ profiles in volcanic plumes from the NASA Tropospheric Emission Spectrometer (TES), Geophys. Res. Lett., 35, L22807, https://doi.org/10.1029/2008GL035566, 2008.

Cole-Dai, J.: Volcanoes and climate, WIREs Clim. Change, 1, 824839, https://doi.org/10.1002/wcc.76, 2010.

Cole-Dai, J., Ferris, D. G., Lanciki, A. L., Savarino, J., Thiemens, M. H., and McConnell, J. R.: Two likely stratospheric volcanic eruptions in the 1450 s C.E. found in a bipolar, subannually dated 800 year ice core record, J. Geophys. Res.-Atmos., 118, 7459-7466, https://doi.org/10.1002/jgrd.50587, 2013.

Crowley, T. J. and Unterman, M. B.: Technical details concerning development of a $1200 \mathrm{yr}$ proxy index for global volcanism, Earth Syst. Sci. Data, 5, 187-197, https://doi.org/10.5194/essd5-187-2013, 2013.

Crowley, T., Zielinski, G., Vinther, B. M., Udisti, R., Kreutz, K., Cole-Dai, J., and Castellano, E.: Volcanism and the little ice age, PAGES Newsl., 16, 22-23, 2008.

Crutzen, P. J.: The possible importance of CSO for the sulfate layer of the stratosphere, Geophys. Res. Lett., 3, 73-76, https://doi.org/10.1029/GL003i002p00073, 1976.

Dhomse, S. S., Emmerson, K. M., Mann, G. W., Bellouin, N., Carslaw, K. S., Chipperfield, M. P., Hommel, R., Abraham, N. L., Telford, P., Braesicke, P., Dalvi, M., Johnson, C. E., O'Connor, F., Morgenstern, O., Pyle, J. A., Deshler, T., Zawodny, J. M., and Thomason, L. W.: Aerosol microphysics simulations of the Mt. Pinatubo eruption with the UM-UKCA composition-climate model, Atmos. Chem. Phys., 14, 1122111246, https://doi.org/10.5194/acp-14-11221-2014, 2014.

Dunn, G.: Design and analysis of reliability studies: The statistical evaluation of measurement errors, New York: Oxford University Press, 1989.

English, J. M., Toon, O. B., and Mills, M. J.: Microphysical simulations of large volcanic eruptions: Pinatubo and Toba, J. Geophys. Res.-Atmos., 118, 1-16, https://doi.org/10.1002/jgrd.50196, 2013. 
Ferris, D. G., Cole-Dai, J., Reyes, A. R., and Budner, D. M.: South Pole ice core record of explosive volcanic eruptions in the first and second millennia A. D., and evidence of a large eruption in the tropics around 535 A.D., J. Geophys. Res.-Atmos., 116, D17308, https://doi.org/10.1029/2011JD015916, 2011.

Gao, C., Robock, A., Self, S., Witter, J. B., Steffenson, J. P., Clausen, H. B., Siggaard-Andersen, M.-L., Johnsen, S., Mayewski, P. A., and Ammann, C.: The 1452 or 1453 A. D. Kuwae eruption signal derived from multiple ice core records: greatest volcanic sulfate event of the past 700 years, J. Geophys. Res.-Atmos., 111, D12107, https://doi.org/10.1029/2005JD006710, https://doi.org/10.1029/2005JD006710, 2006.

Gao, C., Oman, L., Robock, A., and Stenchikov, G. L.: Atmospheric volcanic loading derived from bipolar ice cores: accounting for the spatial distribution of volcanic deposition, J. Geophys. Res.Atmos., 112, D09109, https://doi.org/10.1029/2006JD007461, 2007.

Gao, C., Robock, A., and Ammann, C.: Volcanic forcing of climate over the past 1500 years: an improved ice core-based index for climate models, J. Geophys. Res.-Atmos., 113, D23111, https://doi.org/10.1029/2008JD010239, 2008.

Gautier, E., Savarino, J., Erbland, J., Lanciki, A., and Possenti, P.: Variability of sulfate signal in ice core records based on five replicate cores, Clim. Past, 12, 103-113, https://doi.org/10.5194/cp12-103-2016, 2016.

Global Volcanism Program: Volcanoes of the World, v. 4.5.0, in Smithsonian Institution, edited by: Venzke, E., available at: https://doi.org/10.5479/si.GVP.VOTW4-2013, last access: 12 April 2016, 2013.

Guo, S., Bluth, G. J. S., Rose, W. I., Watson, I. M., and Prata, A. J.: Re-evaluation of $\mathrm{SO}_{2}$ release of the 15 Jun 1991 Pinatubo eruption using ultraviolet and infrared satellite sensors, Geochem. Geophy. Geosy., 5, Q04001, https://doi.org/10.1029/2003GC000654, 2004.

Hayakawa, Y. and Koyama, M.: Dates of two major eruptions from Towada and Baitoushan in the 10th century, B. Volcanol. Soc. Japan, 43, 403-407, 1998.

Hegerl, G. C., Crowley, T. J., Allen, M., Hyde, W. T., Pollack, H. N., Smerdon, J., and Zorita, E.: Detection of human influence on a new, validated 1500-year temperature reconstruction, J. Climate, 20, 650-666, https://doi.org/10.1175/JCLI4011.1, 2007.

Hogg, A., Lowe, D. J., Palmer, J., Boswijk, G., and Ramsey, C. B.: Revised calendar date for the Taupo eruption derived by ${ }^{14} \mathrm{C}$ wiggle-matching using a New Zealand kauri ${ }^{14} \mathrm{C}$ calibration data set, Holocene, 22, 439-449, https://doi.org/10.1177/0959683611425551, 2012.

Höpfner, M., Boone, C. D., Funke, B., Glatthor, N., Grabowski, U., Günther, A., Kellmann, S., Kiefer, M., Linden, A., Lossow, S., Pumphrey, H. C., Read, W. G., Roiger, A., Stiller, G., Schlager, H., von Clarmann, T., and Wissmüller, K.: Sulfur dioxide $\left(\mathrm{SO}_{2}\right)$ from MIPAS in the upper troposphere and lower stratosphere 2002-2012, Atmos. Chem. Phys., 15, 7017-7037, https://doi.org/10.5194/acp-15-7017-2015, 2015.

Isobe, T., Feigelson, E. D., Akritas, M. G., and Babu, G. J.: Linear regression in astronomy, Astrophys. J., 364, 104, https://doi.org/10.1086/169390, 1990.

Jensen, B. J. L., Pyne-O’Donnell, S., Plunkett, G., Froese, D. G., Hughes, P. D. M., Sigl, M., McConnell, J. R., Amesbury, M. J.,
Blackwell, P. G., van den Bogaard, C., Buck, C. E., Charman, D. J., Clague, J. J., Hall, V. A., Koch, J., Mackay, H., Mallon, G., McColl, L., and Pilcher, J. R.: Transatlantic distribution of the Alaskan White River Ash, Geology, 42, 875-878, https://doi.org/10.1130/G35945.1, 2014.

Jungclaus, J. H., Bard, E., Baroni, M., Braconnot, P., Cao, J., Chini, L. P., Egorova, T., Evans, M., González-Rouco, J. F., Goosse, H., Hurtt, G. C., Joos, F., Kaplan, J. O., Khodri, M., Klein Goldewijk, K., Krivova, N., LeGrande, A. N., Lorenz, S. J., Luterbacher, J., Man, W., Meinshausen, M., Moberg, A., Nehrbass-Ahles, C., Otto-Bliesner, B. I., Phipps, S. J., Pongratz, J., Rozanov, E., Schmidt, G. A., Schmidt, H., Schmutz, W., Schurer, A., Shapiro, A. I., Sigl, M., Smerdon, J. E., Solanki, S. K., Timmreck, C., Toohey, M., Usoskin, I. G., Wagner, S., Wu, C.-Y., Yeo, K. L., Zanchettin, D., Zhang, Q., and Zorita, E.: The PMIP4 contribution to CMIP6 - Part 3: the Last Millennium, Scientific Objective and Experimental Design for the PMIP4 past1000 simulations, Geosci. Model Dev. Discuss., https://doi.org/10.5194/gmd-2016278, in press, 2016.

Junge, C. E., Chagnon, C. W., Manson, J. E., Junge, C. E., Chagnon, C. W., and Manson, J. E.: Stratospheric aerosols, J. Meteorol., 18, 81-108, https://doi.org/10.1175/15200469(1961)018<0081:SA>2.0.CO;2, 1961.

Kremser, S., Thomason, L. W., von Hobe, M., Hermann, M., Deshler, T., Timmreck, C., Toohey, M., Stenke, A., Schwarz, J. P., Weigel, R., Fueglistaler, S., Prata, F. J., Vernier, J.-P., Schlager, H., Barnes, J. E., Antuña-Marrero, J.-C., Fairlie, D., Palm, M., Mahieu, E., Notholt, J., Rex, M., Bingen, C., Vanhellemont, F., Bourassa, A., Plane, J. M. C., Klocke, D., Carn, S. A., Clarisse, L., Trickl, T., Neely, R., James, A. D., Rieger, L., Wilson, J. C., and Meland, B.: Stratospheric aerosol - observations, processes, and impact on climate, Rev. Geophys., 54, 278-335, https://doi.org/10.1002/2015RG000511, 2016.

Lamb, H. H.: Volcanic dust in the atmosphere; with a chronology and assessment of its meteorological significance, Philos. T. Roy. Soc. A, 266, 425-533, 1970.

Lanciki, A., Cole-Dai, J., Thiemens, M. H., and Savarino, J.: Sulfur isotope evidence of little or no stratospheric impact by the 1783 Laki volcanic eruption, Geophys. Res. Lett., 39, L01806, https://doi.org/10.1029/2011GL050075, 2012.

Lavigne, F., Degeai, J.-P., Komorowski, J.-C., Guillet, S., Robert, V., Lahitte, P., Oppenheimer, C., Stoffel, M., Vidal, C. M., Surono, Pratomo, I., Wassmer, P., Hajdas, I., Hadmoko, D. S., and de Belizal, E.: Source of the great A.D. 1257 mystery eruption unveiled, Samalas volcano, Rinjani Volcanic Complex, Indonesia, P. Natl. Acad. Sci. USA, 110, 16742 16747, https://doi.org/10.1073/pnas.1307520110, 2013.

Ludlow, F., Stine, A. R., Leahy, P., Murphy, E., Mayewski, P. A., Taylor, D., Killen, J., Baillie, M. G. L., Hennessy, M., and Kiely, G.: Medieval Irish chronicles reveal persistent volcanic forcing of severe winter cold events, 431-1649 CE, Environ. Res. Lett., 8, 24035, https://doi.org/10.1088/1748-9326/8/2/024035, 2013.

Luo, B.: Stratospheric aerosol data for use in CMIP6 models, available at: ftp://iacftp.ethz.ch/pub_read/luo/CMIP6/, last access: 21 November 2016.

Marshall, L., Schmidt, A., Toohey, M., Carslaw, K. S., Mann, G. W., Sigl, M., Khodri, M., Timmreck, C., Zanchettin, D., Ball, W., Bekki, S., Brooke, J. S. A., Dhomse, S., Johnson, C., Lamar- 
que, J.-F., LeGrande, A., Mills, M. J., Niemeier, U., Poulain, V., Robock, A., Rozanov, E., Stenke, A., Sukhodolov, T., Tilmes, S., Tsigaridis, K., and Tummon, F.: Multi-model comparison of the volcanic sulfate deposition from the 1815 eruption of Mt. Tambora, Atmos. Chem. Phys. Discuss., in review, 2017.

Masson-Delmotte, V., Schulz, M., Abe-Ouchi, A., Beer, J., Ganopolski, A., Gonzalez Rouco, J. F., Jansen, E., Lambeck, K., Luterbacher, J., Naish, T., Osborn, T., Otto-Bliesner, B., Quinn, T., Ramesh, R., Rojas, M., Shao, X., and Timmermann, A.: Information from Paleoclimate Archives, in: Climate Change 2013: The Physical Science Basis. Contribution of Working Group I to the Fifth Assessment Report of the Intergovernmental Panel on Climate Change, edited by: Stocker, T. F., Qin, D., Plattner, G.-K., Tignor, M., Allen, S. K., Boschung, J., Nauels, A., Xia, Y., Bex, V., and Midgley, P. M., Cambridge University Press, Cambridge, UK and New York, NY, USA, 2013.

Metzner, D., Kutterolf, S., Toohey, M., Timmreck, C., Niemeier, U., Freundt, A., and Krüger, K.: Radiative forcing and climate impact resulting from $\mathrm{SO}_{2}$ injections based on a 200,000year record of Plinian eruptions along the Central American Volcanic Arc, Int. J. Earth Sci., 103, 2063-2079, https://doi.org/10.1007/s00531-012-0814-z, 2012.

Mills, M. J., Schmidt, A., Easter, R., Solomon, S., Kinnison, D. E., Ghan, S. J., Neely, R. R., Marsh, D. R., Conley, A., Bardeen, C. G., and Gettelman, A.: Global volcanic aerosol properties derived from emissions, 1990-2014, using CESM1(WACCM), J. Geophys. Res.-Atmos., 121, 2332-2348, https://doi.org/10.1002/2015JD024290, 2016.

Mosley-Thompson, E., Thompson, L. G., Dai, J., Davis, M., and Lin, P. N.: Climate of the last 500 years: high resolution ice core records, Quaternary Sci. Rev., 12, 419-430, https://doi.org/10.1016/S0277-3791(05)80006-X, 1993.

Neely III, R. R. and Schmidt, A.: VolcanEESM: Global volcanic sulphur dioxide (SO2) emissions database from 1850 to present Version 1.0. Centre for Environmental Data Analysis, 4 February 2016, available at: https://doi.org/10.5285/76ebdc0b-0eed-4f70b89e-55e606bcd568 (last access: January 2016), 2016.

Neu, J. L., Sparling, L. C., and Plumb, R. A.: Variability of the subtropical "edges" in the stratosphere, J. Geophys. Res.-Atmos., 108, 4482, https://doi.org/10.1029/2002JD002706, 2003.

Oman, L., Robock, A., Stenchikov, G. L., Thordarson, T., Koch, D., Shindell, D. T., and Gao, C.: Modeling the distribution of the volcanic aerosol cloud from the 17831784 Laki eruption, J. Geophys. Res.-Atmos., 111, D12209, https://doi.org/10.1029/2005JD006899, 2006.

Oppenheimer, C.: Eruptions That Shook the World, Cambridge University Press, Cambridge UK, 2011.

Oppenheimer, C., Orchard, A., Stoffel, Newfield, T. P., M., Guillet, S., Corona, C., Sigl, M., and Büntgen, U.: Timing and consequences of the Eldgjá lava flood eruption, Iceland, in preparation, 2017.

Pasteris, D., McConnell, J. R., Edwards, R., Isaksson, E., and Albert, M. R.: Acidity decline in Antarctic ice cores during the Little Ice Age linked to changes in atmospheric nitrate and sea salt concentrations, J. Geophys. Res.-Atmos., 119, 5640-5652, https://doi.org/10.1002/2013JD020377, 2014.

Plummer, C. T., Curran, M. A. J., van Ommen, T. D., Rasmussen, S. O., Moy, A. D., Vance, T. R., Clausen, H. B., Vinther, B. M., and Mayewski, P. A.: An independently dated 2000-yr vol- canic record from Law Dome, East Antarctica, including a new perspective on the dating of the 1450s CE eruption of Kuwae, Vanuatu, Clim. Past, 8, 1929-1940, https://doi.org/10.5194/cp8-1929-2012, 2012.

Pyle, D. M., Beattie, P. D., and Bluth, G. J. S.: Sulphur emissions to the stratosphere from explosive volcanic eruptions, B. Volcanol., 57, 663-671, https://doi.org/10.1007/s004450050119, 1996.

Read, W. G., Froidevaux, L., and Waters, J. W.: Microwave limb sounder measurement of stratospheric $\mathrm{SO}_{2}$ from the Mt. Pinatubo Volcano, Geophys. Res. Lett., 20, 1299, https://doi.org/10.1029/93GL00831, 1993.

Robock, A.: Volcanic eruptions and climate, Rev. Geophys., 38, 191-219, https://doi.org/10.1029/1998RG000054, 2000.

Robock, A. and Free, M. P.: Ice cores as an index of global volcanism from 1850 to the present, J. Geophys. Res.-Atmos., 100, 11549-11567, https://doi.org/10.1029/95JD00825, 1995.

Sato, M., Hansen, J. E., McCormick, M. P., and Pollack, J. B.: Stratospheric aerosol optical depths, 18501990, J. Geophys. Res.-Atmos., 98, 22987-22994, https://doi.org/10.1029/93JD02553, 1993.

Scaillet, B., Luhr, J. F., and Carroll, M. R.: Petrological and volcanological constraints on volcanic sulfur emissions to the atmosphere, in Volcanism and the Earth's Atmosphere, vol. 139, edited by: Robock, A., Oppenheimer, C., American Geophysical Union, Washington, D. C., 11-40, 2003.

Schmidt, G. A., Jungclaus, J. H., Ammann, C. M., Bard, E., Braconnot, P., Crowley, T. J., Delaygue, G., Joos, F., Krivova, N. A., Muscheler, R., Otto-Bliesner, B. L., Pongratz, J., Shindell, D. T., Solanki, S. K., Steinhilber, F., and Vieira, L. E. A.: Climate forcing reconstructions for use in PMIP simulations of the last millennium (v1.0), Geosci. Model Dev., 4, 33-45, https://doi.org/10.5194/gmd-4-33-2011, 2011.

Schmidt, A., Thordarson, T., Oman, L. D., Robock, A., and Self, S.: Climatic impact of the long-lasting 1783 Laki eruption: inapplicability of mass-independent sulfur isotopic composition measurements, J. Geophys. Res.-Atmos., 117, D23116, https://doi.org/10.1029/2012JD018414, 2012.

Schmidt, A., Leadbetter, S., Theys, N., Carboni, E., Witham, C. S., Stevenson, J. A., Birch, C. E., Thordarson, T., Turnock, S., Barsotti, S., Delaney, L., Feng, W., Grainger, R. G., Hort, M. C., Höskuldsson, Á., Ialongo, I., Ilyinskaya, E., Jóhannsson, T., Kenny, P., Mather, T. A., Richards, N. A. D., and Shepherd, J.: Satellite detection, long-range transport, and air quality impacts of volcanic sulfur dioxide from the 2014-2015 flood lava eruption at Bárðarbunga (Iceland), J. Geophys. Res.-Atmos., 120, 9739-9757, https://doi.org/10.1002/2015JD023638, 2015.

Schurer, A. P., Hegerl, G. C., Mann, M. E., Tett, S. F. B., and Phipps, S. J.: Separating forced from chaotic climate variability over the past millennium, J. Climate, 26, 6954-6973, https://doi.org/10.1175/JCLI-D-12-00826.1, 2013.

Self, S.: Magma volume, volatile emissions, and stratospheric aerosols from the 1815 eruption of Tambora, Geophys. Res. Lett., 31, L20608, https://doi.org/10.1029/2004GL020925, 2004.

Self, S. and King, A. J.: Petrology and sulfur and chlorine emissions of the 1963 eruption of Gunung Agung, Bali, Indonesia, B. Volcanol., 58, 263-285, https://doi.org/10.1007/s004450050139, 1996.

Sheng, J.-X., Weisenstein, D. K., Luo, B.-P., Rozanov, E., Stenke, A., Anet, J., Bingemer, H., and Peter, T.: Global 
atmospheric sulfur budget under volcanically quiescent conditions: aerosol-chemistry-climate model predictions and validation, J. Geophys. Res.-Atmos., 120, 256-276, https://doi.org/10.1002/2014JD021985, 2015.

Sigl, M., McConnell, J. R., Layman, L., Maselli, O., McGwire, K., Pasteris, D., Dahl-Jensen, D., Steffensen, J. P., Vinther, B., Edwards, R., Mulvaney, R., and Kipfstuhl, S.: A new bipolar ice core record of volcanism from WAIS Divide and NEEM and implications for climate forcing of the last 2000 years, J. Geophys. Res.-Atmos., 118, 1151-1169, https://doi.org/10.1029/2012JD018603, 2013.

Sigl, M., McConnell, J. R., Toohey, M., Curran, M., Das, S. B., Edwards, R., Isaksson, E., Kawamura, K., Kipfstuhl, S., Krüger, K., Layman, L., Maselli, O. J., Motizuki, Y., Motoyama, H., Pasteris, D. R., and Severi, M.: Insights from Antarctica on volcanic forcing during the Common Era, Nat. Clim. Change, 4, 693-697, https://doi.org/10.1038/nclimate2293, 2014.

Sigl, M., Winstrup, M., McConnell, J. R., Welten, K. C., Plunkett, G., Ludlow, F., Büntgen, U., Caffee, M., Chellman, N., Dahl-Jensen, D., Fischer, H., Kipfstuhl, S., Kostick, C., Maselli, O. J., Mekhaldi, F., Mulvaney, R., Muscheler, R., Pasteris, D. R., Pilcher, J. R., Salzer, M., Schüpbach, S., Steffensen, J. P., Vinther, B. M., and Woodruff, T. E.: Timing and climate forcing of volcanic eruptions for the past 2,500 years, Nature, 523, 543-549, https://doi.org/10.1038/nature14565, 2015.

Sigl, M., Fudge, T. J., Winstrup, M., Cole-Dai, J., Ferris, D., McConnell, J. R., Taylor, K. C., Welten, K. C., Woodruff, T. E., Adolphi, F., Bisiaux, M., Brook, E. J., Buizert, C., Caffee, M. W., Dunbar, N. W., Edwards, R., Geng, L., Iverson, N., Koffman, B., Layman, L., Maselli, O. J., McGwire, K., Muscheler, R., Nishiizumi, K., Pasteris, D. R., Rhodes, R. H., and Sowers, T. A.: The WAIS Divide deep ice core WD2014 chronology Part 2: Annual-layer counting (0-31 ka BP), Clim. Past, 12, 769786, https://doi.org/10.5194/cp-12-769-2016, 2016.

Sigurdsson, H. and Carey, S.: Plinian and co-ignimbrite tephra fall from the 1815 eruption of Tambora volcano, B. Volcanol., 51, 243-270, https://doi.org/10.1007/BF01073515, 1989.

Stothers, R. B.: Major optical depth perturbations to the stratosphere from volcanic eruptions: pyrheliometric period, 1881-1960, J. Geophys. Res.-Atmos., 101, 3901-3920, https://doi.org/10.1029/95JD03237, 1996.

Stothers, R. B.: Major optical depth perturbations to the stratosphere from volcanic eruptions: stellar extinction period, 1961-1978, J. Geophys. Res.-Atmos., 106, 2993-3003, https://doi.org/10.1029/2000JD900652, 2001.

Sun, C., Plunkett, G., Liu, J., Zhao, H., Sigl, M., McConnell, J. R., Pilcher, J. R., Vinther, B., Steffensen, J. P., and Hall, V.: Ash from Changbaishan Millennium eruption recorded in Greenland ice: implications for determining the eruption's timing and impact, Geophys. Res. Lett., 41, 694-701, https://doi.org/10.1002/2013GL058642, 2014.

Thordarson, T. and Larsen, G.: Volcanism in Iceland in historical time: volcano types, eruption styles and eruptive history, J. Geodyn., 43, 118-152, https://doi.org/10.1016/j.jog.2006.09.005, 2007.

Thordarson, T. and Self, S.: Atmospheric and environmental effects of the 1783-1784 Laki eruption: a review and reassessment, J. Geophys. Res.-Atmos., 108, 4011, https://doi.org/10.1029/2001JD002042, 2003.
Timmreck, C.: Modeling the climatic effects of large explosive volcanic eruptions, WIREs Clim. Change, 3, 545-564, https://doi.org/10.1002/wcc.192, 2012.

Toohey, M. and Sigl, M.: Reconstructed volcanic stratospheric sulfur injections and aerosol optical depth, $500 \mathrm{BCE}$ to $1900 \mathrm{CE}$, version 2, World Data Center for Climate (WDCC) at DKRZ, https://doi.org/10.1594/WDCC/eVolv2k_v2 (last access: 17 May 2017), 2017.

Toohey, M. and Strong, K.: Estimating biases and error variances through the comparison of coincident satellite measurements, J. Geophys. Res.-Atmos., 112, D13306, https://doi.org/10.1029/2006JD008192, 2007.

Toohey, M., Krüger, K., Niemeier, U., and Timmreck, C.: The influence of eruption season on the global aerosol evolution and radiative impact of tropical volcanic eruptions, Atmos. Chem. Phys., 11, 12351-12367, https://doi.org/10.5194/acp-11-123512011, 2011.

Toohey, M., Krüger, K., and Timmreck, C.: Volcanic sulfate deposition to Greenland and Antarctica: a modeling sensitivity study, J. Geophys. Res.-Atmos., 118, 4788-4800, https://doi.org/10.1002/jgrd.50428, 2013.

Toohey, M., Krüger, K., Sigl, M., Stordal, F., and Svensen, H.: Climatic and societal impacts of a volcanic double event at the dawn of the Middle Ages, Climatic Change, 136, 401-412, https://doi.org/10.1007/s10584-016-1648-7, 2016a.

Toohey, M., Stevens, B., Schmidt, H., and Timmreck, C.: Easy Volcanic Aerosol (EVA v1.0): an idealized forcing generator for climate simulations, Geosci. Model Dev., 9, 4049-4070, https://doi.org/10.5194/gmd-9-4049-2016, 2016 b.

Traufetter, F., Oerter, H., Fischer, H., Weller, R., and Miller, H.: Spatio-temporal variability in volcanic sulphate deposition over the past $2 \mathrm{kyr}$ in snow pits and firn cores from Amundsenisen, Antarctica, J. Glaciol., 50, 137-146, 2004.

Xu, J., Pan, B., Liu, T., Hajdas, I., Zhao, B., Yu, H., Liu, R., and Zhao, P.: Climatic impact of the Millennium eruption of Changbaishan volcano in China: new insights from high-precision radiocarbon wiggle-match dating, Geophys. Res. Lett., 40, 54-59, https://doi.org/10.1029/2012GL054246, 2013.

Zanchettin, D., Khodri, M., Timmreck, C., Toohey, M., Schmidt, A., Gerber, E. P., Hegerl, G., Robock, A., Pausata, F. S. R., Ball, W. T., Bauer, S. E., Bekki, S., Dhomse, S. S., LeGrande, A. N., Mann, G. W., Marshall, L., Mills, M., Marchand, M., Niemeier, U., Poulain, V., Rozanov, E., Rubino, A., Stenke, A., Tsigaridis, K., and Tummon, F.: The Model Intercomparison Project on the climatic response to Volcanic forcing (VolMIP): experimental design and forcing input data for CMIP6, Geosci. Model Dev., 9, 2701-2719, https://doi.org/10.5194/gmd-9-2701-2016, 2016.

Zielinski, G. A.: Stratospheric loading and optical depth estimates of explosive volcanism over the last 2100 years derived from the Greenland Ice Sheet Project 2 ice core, J. Geophys. Res.-Atmos., 100, 20937-20955, https://doi.org/10.1029/95JD01751, 1995.

Zielinski, G.: A 110,000-Yr record of explosive volcanism from the GISP2 (Greenland) ice core, Quaternary Res., 45, 109-118, https://doi.org/10.1006/qres.1996.0013, 1996. 